ano 15 - n. 61 I julho/setembro - 2015

Belo Horizonte I p. 1-270 I ISSN 1516-3210

A\&C - R. de Dir. Administrativo \& Constitucional

Revista de Direito ADMINISTRATIVO \& CONSTITUCIONAL

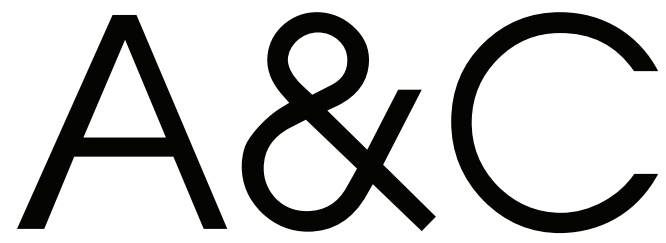




\section{A\&C - REVISTA DE DIREITO ADMINISTRATIVO \& CONSTITUCIONAL}

IPDA

Instituto Paranaense

de Direito Administrativo
ROMEU DEUPE

BACELLAR

๑) 2015 Editora Fórum Ltda.

Todos os direitos reservados. É proibida a reprodução total ou parcial, de qualquer forma ou por qualquer meio eletrônico ou mecânico, inclusive através de processos xerográficos, de fotocópias ou de gravação, sem permissão por escrito do possuidor dos direitos de cópias (Lei no 9.610, de 19.02.1998).

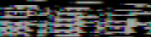

Luís Cláudio Rodrigues Ferreira

Presidente e Editor

Av. Afonso Pena, 2770 - 16ํandar - Funcionários - CEP 30130-007 - Belo Horizonte/MG - Brasil - Tel.: 08007043737 www.editoraforum.com.br / E-mail: editoraforum@editoraforum.com.br

Impressa no Brasil / Printed in Brazil / Distribuída em todo o Território Nacional

Os conceitos e opiniões expressas nos trabalhos assinados são de responsabilidade exclusiva de seus autores.

A246 A\&C : Revista de Direito Administrativo \&
Constitucional. - ano 3, n. 11, jan./mar.
2003)- . - Belo Horizonte: Fórum, 2003-
Trimestral
ISSN: 1516-3210
Ano 1, n. 1, 1999 até ano 2, n. 10, 2002 publicada
pela Editora Juruá em Curitiba
$\begin{aligned} & \text { 1. Direito administrativo. 2. Direito constitucional. } \\ & \text { I. Fórum. } \\ & \text { CDD: } 342 \\ & \text { CDU: } 342.9\end{aligned}$

Supenvisão editorial: Leonardo Eustáquio Siqueira Araújo

Capa: Igor Jamur

Projeto gráfico: Walter Santos

\section{Periódico classificado no Estrato A1 do Sistema Qualis da CAPES - Área: Direito.}

Revista do Programa de Pós-graduação do Instituto de Direito Romeu Felipe Bacellar (Instituição de Pesquisa e Pós-Graduação), em convênio com o Instituto Paranaense de Direito Administrativo (entidade associativa de âmbito regional filiada ao Instituto Brasileiro de Direito Administrativo). A linha editorial da $A \& C$ - Revista de Direito Administrativo \& Constitucional segue as diretrizes do Programa de Pós-Graduação do Instituto de Direito Romeu Felipe Bacellar em convênio com o Instituto Paranaense de Direito Administrativo. Procura divulgar as pesquisas desenvolvidas na área de Direito Constitucional e de Direito Administrativo, com foco na questão da efetividade dos seus institutos não só no Brasil como no direito comparado, com ênfase na questão da interação e efetividade dos seus institutos, notadamente América Latina e países europeus de cultura latina.

A publicação é decidida com base em pareceres, respeitando-se o anonimato tanto do autor quanto dos pareceristas (sistema double-blind peer review).

Desde o primeiro número da Revista, $75 \%$ dos artigos publicados (por volume anual) são de autores vinculados a pelo menos cinco instituições distintas do Instituto de Direito Romeu Felipe Bacellar.

A partir do volume referente ao ano de 2008 , pelo menos $15 \%$ dos artigos publicados são de autores filiados a instituições estrangeiras.

Esta publicação está catalogada em:

- Ulrich's Periodicals Directory

- RVBI (Rede Virtual de Bibliotecas - Congresso Nacional)

- Library of Congress (Biblioteca do Congresso dos EUA)

A\&C - Revista de Direito Administrativo \& Constitucional realiza permuta com as seguintes publicações: - Revista da Faculdade de Direito, Universidade de São Paulo (USP), ISSN 0303-9838

- Rivista Diritto Pubblico Comparato ed Europeo, ISBN/EAN 978-88-348-9934-2 
Diretor-Geral

Romeu Felipe Bacellar Filho

Diretor Editorial

Paulo Roberto Ferreira Motta

Editores Acadêmicos Responsáveis

Daniel Wunder Hachem

Ana Cláudia Finger

Assessor Editorial

Felipe Klein Gussoli

\section{Conselho Editorial}

Adilson Abreu Dallari (PUC-SP) Juan Pablo Cajarville Peluffo (Universidad de La República - Uruguai) ardo Schier (Instituto Bacellar) Justo J. Reyna (Universidad Nacional del Litoral - Argentina)

Alice Gonzalez Borges (UFBA) Juarez Freitas (UFRGS)

Carlos Ari Sundfeld (FGV-SP) Luís Enrique Chase Plate (Universidad Nacional de Asunción - Paraguai)

Carlos Ayres Britto (UFSE) Marçal Justen Filho (UFPR)

Adriana da Costa Ricardo Schier (Instituto Bacellar)
Alice Gonzalez Borges (UFBA)

Marcelo Figueiredo (PUC-SP)

Márcio Cammarosano (PUC-SP)

Carlos Delpiazzo (Universidad de La República - Uruguai) Cármen Lúcia Antunes Rocha (PUC Minas) Célio Heitor Guimarães (Instituto Bacellar) Celso Antônio Bandeira de Mello (PUC-SP) Clèmerson Merlin Clève (UFPR) Clovis Beznos (PUC-SP) Edgar Chiuratto Guimarães (Instituto Bacellar) Maria Cristina Cesar de Oliveira (UFPA)

Nelson Figueiredo (UFG)

Odilon Borges Junior (UFES)

Pascual Caiella (Universidad de La Plata - Argentina)

Emerson Gabardo (UFPR)

Paulo Eduardo Garrido Modesto (UFBA)

Paulo Henrique Blasi (UFSC)

Enrique Silva Cimma (Universidad de Chile - Chile) Eros Roberto Grau (USP)

Irmgard Elena Lepenies (Universidad Nacional del Litoral - Argentina) de La Coruña - Espanha)

Pedro Paulo de Almeida Dutra (UFMG)

Regina Maria Macedo Nery Ferrari (UFPR)

Rogério Gesta Leal (UNISC)

Rolando Pantoja Bauzá (Universidad Nacional de Chile - Chile)

Sergio Ferraz (PUC-Rio)

Valmir Pontes Filho (UFCE)

José Eduardo Martins Cardoso (PUC-SP)

José Luís Said (Universidad de Buenos Aires - Argentina) José Mario Serrate Paz (Universidad de Santa Cruz - Bolívia)

Yara Stroppa (PUC-SP)

\section{Homenagem Especial}

Guillermo Andrés Muñoz (in memoriam) Jorge Luís Salomoni (in memoriam) Julio Rodolfo Comadira (in memoriam) Lúcia Valle Figueiredo (in memoriam)

Manoel de Oliveira Franco Sobrinho (in memoriam) Paulo Neves de Carvalho (in memoriam) 


\title{
Da necessidade de uma política pública voltada aos medicamentos para doenças raras
}

\section{Joseane Ledebrum Gloeckner}

Mestra em Direito pela Pontifícia Universidade Católica do Rio Grande do Sul - PUCRS (Porto Alegre - RS). Especialista em Direito Público pela PUCRS. Advogada. E-mail: $<$ joseaneledebrum@hotmail.com>.

\begin{abstract}
Resumo: Este estudo teve por objeto os medicamentos destinados ao tratamento de doenças raras, que deixam de ser fabricados pelos laboratórios farmacêuticos por trazerem pouca lucratividade. Constatouse que o ordenamento jurídico brasileiro oferece alguns mecanismos que podem garantir o acesso aos medicamentos para os portadores de doenças raras, como é o caso do licenciamento compulsório e da importação paralela. No entanto, tais mecanismos resolvem o problema de um medicamento de cada vez e não se prestam à solução do caso. Buscou-se, então, analisar as políticas públicas implementadas pelos Estados Unidos e pela União Europeia para incentivar a pesquisa, fabricação e continuidade na produção dos medicamentos destinados às doenças raras. Concluiu-se que também o Brasil deveria instituir uma política pública destinada exclusivamente à fabricação destes fármacos a fim de que se possa garantir efetivamente o direito fundamental à saúde.
\end{abstract}

Palavras-chave: Medicamento. Doença rara. Política pública.

Sumário: Introdução - 10 caso das doenças raras e do medicamento órfão - $\mathbf{2}$ Da repercussão econômica dos medicamentos - Conclusão - Referências

\section{Introdução}

O Direito à saúde, por ser um direito fundamental, social, de cunho predominantemente prestacional e, consequentemente, diretamente aplicável, deve ser prestado pelo Estado. Incluem-se, neste direito à saúde a ser prestado pelo Estado, o fornecimento de medicamentos, até mesmo aqueles que não se encontram nas listas do SUS.

No entanto, quando se trata de medicamentos destinados ao tratamento de doenças raras, surge uma outra questão, essencialmente econômica, quando os laboratórios farmacêuticos deixam de fabricar estes fármacos em virtude da baixa rentabilidade que eles trazem.

\section{O caso das doenças raras e do medicamento órfão}

Dentre as inúmeras doenças da atualidade, existem aquelas mais comuns e corriqueiras, que a maioria das pessoas conhece, e aquelas muito pouco frequentes 
e desconhecidas da maioria. Estas últimas são denominadas de doenças raras. 0 conceito de doença rara é pouco explicado pelo Sistema Único de Saúde brasileiro e pela Agência Nacional de Vigilância Sanitária (ANVISA). No entanto, a Resolução no 28 de 04 de abril de 2007 da ANVISA traz definição para este tipo de doença. Conforme a Resolução, doença rara ou órfã é aquela que afeta um número pequeno de pessoas em comparação com a população em geral.

Em outros países existem definições mais específicas de doença órfã. Há diferenças entre EUA e União Europeia na designação de quando uma doença é considerada rara. Os EUA trabalham com número absoluto, que é menos de 200.000 pacientes no país. Enquanto a União Europeia usa uma medida relativa, menos de 5 casos para cada 10.000 habitantes. Além disso, nos EUA, para ser considerada doença rara, requer-se que o paciente necessite de tratamento durante toda a vida ou que a doença seja degenerativa crônica. Utilizando-se destes requisitos, entre 5.000 e 7.000 doenças podem ser consideradas raras. ${ }^{1}$ Tanto a Comunidade Europeia como os Estados Unidos possuem política de pesquisa e desenvolvimento para tratamento e financiamento destas doenças.

Em virtude de as doenças raras atingirem reduzido número de pacientes, acabam gerando pouco lucro à indústria farmacêutica, pois o medicamento para tratamento destas doenças demanda muito tempo de pesquisas de alto custo, assim como alto custo em sua fabricação. Por estes motivos, estes remédios deixam de ser fabricados pelos laboratórios. São denominados de medicamentos órfãos, definidos na referida Resolução no 28 como sendo aqueles fármacos que se mostrem eficazes no diagnóstico ou tratamento das doenças raras ou negligenciadas. ${ }^{2}$

Explica Haffner ${ }^{3}$ que, por todo o mundo, o alto custo no desenvolvimento de medicamentos sempre desencorajou pesquisas farmacológicas para doenças incomuns. Medicamentos não são desenvolvidos quando lucros são improváveis e custos não puderem ser recuperados. Em virtude da raridade das doenças órfãs, produtos órfãos sofrem com um mercado comercial limitado baseado no custo-benefício para a empresa fabricante.

Oportuno ressaltar que a decisão de deixar de fabricar determinado fármaco independe do sucesso do medicamento, mesmo que devolva ao paciente qualidade de vida e condições de vida participativa na sociedade. É o caso do Penicilamina,

\footnotetext{
STOLK, Pieter; WILLEMEN, Marjolein J. C.; LEUFKENS, Hubert G.N. "Rare Essencials": drugs for rare as essencial medicines. Bulletin of the World Health Organization, n. 84, p. 746, 2006.

2 Conforme Resolução no 28/2007 da ANVISA, doença negligenciada é aquela que não apresenta atrativos econômicos para o desenvolvimento de seus fármacos, pois atinge predominantemente a população de países em desenvolvimento. A tuberculose é considerada uma doença negligenciada pela ciência e pela indústria, considerando que são praticamente inexistentes inovações terapêuticas nesta área, conforme BRASIL. Conselho Nacional de Saúde. Assistência Farmacêutica no SUS. Brasília: CONASS, 2011. p. 68.

3 HAFFNER, Marlene E. The United States Orphan Drug Act: challenges and success. Drug Information Jornal, v. 31, p. 23, 1997.
} 
importante e decisivo fármaco no tratamento da Doença de Wilson, ${ }^{4}$ que foi retirado do mercado pelos fabricantes, somente retornando após denúncia da imprensa e descoberta de seu uso em outras doenças. Pode-se citar, ainda, a Sulfasalazina e a Toxina Tipo A do Clostridium botulinum. ${ }^{5}$

Tendo em vista esta paralização na fabricação de medicamentos destinados ao tratamento de doenças raras, busca-se analisar que medidas podem ser tomadas pelo Poder Público para resolver esta questão.

\section{Da repercussão econômica dos medicamentos}

Contemporaneamente os medicamentos ${ }^{6}$ são de grande importância para a sociedade por diferentes motivos: primeiro porque visam melhorar o tratamento da saúde, combatendo enfermidades e reduzindo suas consequências; além disso, apresentam repercussões no setor econômico, pois em uma sociedade capitalista, motivada no lucro, o desenvolvimento de medicamentos passou a apresentar fortes repercussões econômicas. Isso porque a produção de medicamentos é resultado de investimentos de laboratórios no estudo, análise e desenvolvimento de novas pesquisas que visam alcançar resultados medicinais para o tratamento de doenças. ${ }^{7}$

o processo de desenvolvimento de um novo fármaco demanda, na maioria das vezes, altos investimentos. Na Alemanha, o desenvolvimento de fármacos envolve um investimento de aproximadamente 800 milhões de dólares, durando de dez a doze anos (não se desconhece que boa parte destes gastos destina-se a cobrir gastos com propaganda). Tendo em vista o custo e o tempo necessário para o desenvolvimento de um medicamento, a compensação econômica como estímulo parece ser razoável. ${ }^{8}$ o que acontece hoje é que, desde o primeiro momento, a pesquisa está voltada à extração da máxima rentabilidade econômica do produto. ${ }^{9}$

4 Segundo a Associação Brasileira dos Doentes de Wilson, a Doença de Wilson é uma disfunção genética que provoca um acúmulo excessivo de cobre no organismo. Deve ser diagnosticada e tratada antes que o envenenamento por cobre provoque danos graves e até mesmo a morte. Disponível em <www.doençadewilson. org>. Acesso em: 04 maio 2012.

5 SILVA, Regina Célia dos Santos. Medicamentos excepcionais no âmbito da assistência farmacêutica no Brasil. [Mestrado] Fundação Oswaldo Cruz, Escola Nacional de Saúde Pública, 2000. 215p. Disponível em: <http:// portalteses.icict.fiocruz.br/transf.php?script=thes_chap\&id=00006205\&lng=pt\&nrm=iso>. Acesso em: 16 set. 2011.

6 A Lei no 5.991/71 define o medicamento como o produto farmacêutico tecnicamente obtido ou elaborado, com finalidade profilática, curativa, paliativa ou para fins de diagnóstico.

7 BEZERRA, Matheus Ferreira. Patente de Medicamentos: quebra de patente como instrumento de realização do direito. Curitiba: Juruá, 2010. p. 121-126.

8 GRAU-KUNTZ, Karin. Dignidade humana e direito de patentes: sobre o problema de acesso a medicamentos. In: CARVALHO, Patrícia Luciane de (Coord.). Propriedade Intelectual: estudos em homenagem à professora Maristela Basso. Curitiba: Juruá, 2005. p. 309.

9 VELA, Rafaela Barranco. El Estatuto Jurídico de los medicamentos huérfanos em la Unión Europea: el derecho de la salud de los pacientes com enfermidades raras. In: VELA, Rafael Barranco; SÁENZ, Francisco Miguel Bombillar (Org.). El Acceso al Medicamento: retos jurídicos actuales, intervención pública y su vinculación al derecho de la salud. Granada: Editorial Comares, 2010. p. 112. 
Não se pode negar o importante papel desenvolvido pela indústria farmacêutica para a saúde pública da população, mas também não se pode esquecer que os laboratórios farmacêuticos buscam, como qualquer outra empresa, a rentabilidade econômica. ${ }^{10}$ Por este motivo, não se pode estranhar que esta mesma indústria que busca o lucro não tenha interesse na fabricação de medicamentos para doenças raras, já que estas trazem escassa ou nenhuma rentabilidade para estes laboratórios, devido ao reduzido número de pacientes afetados e o gasto em pesquisa e desenvolvimento que geram.

Tendo em vista a grande repercussão econômica da produção e comercialização de medicamentos, o ordenamento jurídico viu-se obrigado a proteger o setor, incluindo os produtos farmacêuticos entre os produtos patenteáveis, com a consequente proteção de sua propriedade intelectual.

\subsection{Da propriedade industrial ${ }^{11}$ dos medicamentos}

Após muitas pressões políticas e econômicas de outros países, o Brasil acabou firmando acordos internacionais, inclusive o Trips, comprometendo-se a proteger a propriedade intelectual dos produtos farmacêuticos. ${ }^{12} \mathrm{~A}$ Constituição Federal brasileira de 1988 previu, então, em seu art. 5ำ, XXIX, ${ }^{13}$ o privilégio patentário como direito e garantia fundamental que visa ao interesse social e ao desenvolvimento tecnológico do país. Assegura, assim, ao titular do invento privilégio temporário de exploração econômica sobre o objeto da invenção. Para regulamentar esta situação, editou-se a Lei № 9.276/96, atual Lei de Patentes que em seu art. $230^{14}$ admite a patenteabilidade de medicamentos.

\subsubsection{Função social da propriedade industrial de medicamentos}

A patente de produtos farmacêuticos, reconhecida pelo ordenamento jurídico brasileiro como espécie de propriedade, assim como qualquer patente de propriedade

10 VELA, Rafaela Barranco. El Estatuto Jurídico de los medicamentos huérfanos em la Unión Europea: el derecho de la salud de los pacientes com enfermidades raras. In: VELA, Rafael Barranco; SÁENZ, Francisco Miguel Bombillar (Org.). El Acceso al Medicamento: retos jurídicos actuales, intervención pública y su vinculación al derecho de la salud. Granada: Editorial Comares, 2010. p. 115

11 A Constituição Federal inclui no âmbito da propriedade intelectual os direitos do autor, o direito à propriedade industrial que inclui o direito às marcas e o direito às patentes.

12 BEZERRA, Matheus Ferreira. Patente de Medicamentos: quebra de patente como instrumento de realização do direito. Curitiba: Juruá, 2010. p. 139.

13 XXIX - a lei assegurará aos autores de inventos industriais privilégio temporário para sua utilização, bem como proteção às criações industriais, à propriedade das marcas, aos nomes de empresas e a outros signos distintivos, tendo em vista o interesse social e o desenvolvimento tecnológico e econômico do País;

14 Art. 230. Poderá ser depositado pedido de patente relativo às substâncias, matérias ou produtos obtidos por meios ou processos químicos e as substâncias, matérias, misturas ou produtos alimentícios, químicofarmacêuticos e medicamentos de qualquer espécie, bem como os respectivos processos de obtenção ou modificação, por quem tenha proteção garantida em tratado ou convenção em vigor no Brasil, ficando assegurada a data do primeiro depósito no exterior, desde que seu objeto não tenha sido colocado em qualquer mercado, por iniciativa direta do titular ou por terceiro com seu consentimento, nem tenham sido realizados, por terceiros, no País, sérios e efetivos preparativos para a exploração do objeto do pedido ou da patente. 
industrial, deverá atender ao princípio da função social, previsto no inciso XXIII15 da Constituição Federal. Isso significa que o uso da invenção não deve ser nocivo ao convívio social e deve ter como finalidade o bem-estar da coletividade. ${ }^{16}$

Após o acordo Trips e a Declaração de Doha não há como delinear o alcance e os limites da propriedade industrial sem considerar a sua função social. No que tange à propriedade industrial, cada vez mais clara está a prevalência do interesse público sobre o interesse privado, especialmente quando se trata de necessidades de saúde pública. ${ }^{17}$

O Acordo Trips já estabelece em seu art. 7ํ18 que a invenção deve ser direcionada não somente à destinação e captação econômica, mas também ao cumprimento do desenvolvimento tecnológico, científico e social. Dessa forma, o titular da patente de medicamentos deverá cumprir com algumas obrigações legais para que o bem patenteado esteja em conformidade com a ordem jurídica e econômica. A propriedade industrial dos medicamentos deve ser exercida na defesa do direito à saúde. Da mesma forma, ao disciplinar sobre a Ordem Econômica, a Constituição Federal, em seu art. 170, estabeleceu que a função social da propriedade deve ser observada pela ordem econômica, buscando assegurar a todos existência digna e justiça social.

Também em seu inciso XXIX $X^{19}$ do art. 5ํㅡ, a Constituição Federal estabelece que a lei assegurará a propriedade industrial tendo em vista o interesse social e o desenvolvimento tecnológico e econômico do país. Deste dispositivo, segundo Barbosa et al., ressalta a vinculação do direito de propriedade o compromisso geral com o uso social da propriedade, através de um vínculo teleológico que perpassa todo o texto constitucional. ${ }^{20}$ Tal conteúdo deve ser analisado em consonância com outras regras constitucionais, especialmente com o art. 219 que prevê incentivos que viabilizem o desenvolvimento socioeconômico, o bem-estar tecnológico e a autonomia tecnológica do país, assim como também o art. 218 , §º, que exige que a pesquisa tecnológica seja voltada, predominantemente, para a solução de problemas brasileiros e para o desenvolvimento do sistema produtivo nacional e regional. Dessa forma, interpretando-se a Constituição de forma sistemática, conclui-se que a proteção da propriedade industrial é garantia a ser exercida de forma balanceada com o

15 XXIII - a propriedade atenderá a sua função social;

16 BEZERRA, Matheus Ferreira. Patente de Medicamentos: quebra de patente como instrumento de realização do direito. p. 90

17 VARGAS, Fábio Aristimunho. O regime internacional de proteção do acesso a medicamentos: um enfoque social. In: CARVALHO, Patrícia Luciane de (Coord.). Propriedade Intelectual: estudos em homenagem à professora Maristela Basso. Curitiba: Juruá, 2005. p. 315.

18 Art. 7 ㅇ.

19 XXIX - a lei assegurará aos autores de inventos industriais privilégio temporário para sua utilização, bem como proteção às criações industriais, à propriedade das marcas, aos nomes de empresas e a outros signos distintivos, tendo em vista o interesse social e o desenvolvimento tecnológico e econômico do País;

20 BARBOSA, Dênis Borges; BARBOSA, Ana Beatriz Nunes; GRAU-KUNTZ, Karin. A Propriedade Intelectual na Construção dos Tribunais Constitucionais. Rio de Janeiro: Lumen Juris, 2009. p. 50. 
interesse da sociedade, em favor da inovação, do progresso tecnológico e do acesso destes bens por aqueles que dele necessitam. ${ }^{21}$ Com o reconhecimento no texto constitucional de proteção exclusiva aos inventores, o sistema de patentes tornou-se o instrumento adequado e efetivo para o fomento do bem-estar social. Pensar que se reconheceria ao inventor um direito exclusivo de exploração econômica de suas invenções, apesar de gerarem efeitos maléficos à sociedade, seria incoerente com os princípios que norteiam a ordem jurídica brasileira. ${ }^{22}$

Quando se fala em medicamento, a função social aparece de forma particular e relevante para a coletividade, pois confronta o direito de propriedade e da livre iniciativa com o direito à vida e à saúde. Segundo a Constituição Federal brasileira, tanto o direito à saúde como o direito à propriedade intelectual são direitos fundamentais. $\mathrm{O}$ acesso aos medicamentos, como integrante do direito à saúde, é direito social. $\mathrm{A}$ propriedade industrial dos medicamentos, como espécie de direito de propriedade, é direito individual com relevância social. Não há condicionantes para o direito à saúde. A propriedade industrial, no entanto, encontra-se condicionada à função social. Para a ordem jurídica nacional, o cumprimento da função social das patentes farmacêuticas corresponde ao respeito ao direito à vida, à dignidade, à justiça social e ao desenvolvimento. ${ }^{23}$

Cabe ressaltar que a efetivação da função social não é ônus exclusivo da iniciativa privada. Pelo contrário, deve ser cumprida principalmente pelo Poder Público. Isso se dá, principalmente, porque a responsabilidade pelo acesso a medicamentos e pela garantia do direito de propriedade industrial cabe ao Estado. A iniciativa privada possui apenas responsabilidade suplementar, pois responsabiliza-se dentro das opções que faz, prestando o direito à saúde ou atuando em sua pesquisa ou desenvolvimento. ${ }^{24}$

Sendo assim, o Estado deve sempre estar atento em relação às patentes de medicamentos, para que a propriedade industrial não se restrinja apenas à obtenção de lucro, deixando de lado a saúde e a vida das pessoas que necessitam do medicamento. Como nem sempre o detentor da patente de produtos farmacêuticos atenderá a função social no exercício de seu direito, caberá ao Estado restabelecer a ordem através de mecanismos de atuação como, por exemplo, a intervenção na propriedade privada. Esta intervenção do Estado na propriedade privada imaterial se dá sobre o direito de exploração com exclusividade da criação. 0 Estado faz a

21 SCUDELER. Marcelo Augusto. A Função Social da Propriedade Industrial. In. VELÁZQUEZ, Victor Hogo Tejerina (Org.). Propriedade Intelectual: setores emergentes e desenvolvimento. Piracicaba: Equilibro, 2007. p. 47.

22 BARBOSA, Dênis Borges; BARBOSA, Ana Beatriz Nunes; GRAU-KUNTZ, Karin. A Propriedade Intelectual na Construção dos Tribunais Constitucionais. Rio de Janeiro: Lumen Juris, 2009. p. 15.

23 CARVALHO, Patrícia Luciane de. Patentes Farmacêuticas e Acesso a Medicamentos. São Paulo: Atlas, 2007. p. 137.

24 CARVALHO, Patrícia Luciane de. Patentes Farmacêuticas e Acesso a Medicamentos. São Paulo: Atlas, 2007. p. 139. 
desconstituição do direito de explorar exclusivamente o bem criado através do Licenciamento Compulsório.

\subsection{Mecanismos já existentes para prestação de medicamentos para portadores de doenças raras}

O Brasil, ao contrário dos Estados Unidos e da União Europeia, não possui política pública voltada especialmente para as doenças raras e o fornecimento de medicamentos para os portadores destas doenças. No entanto, analisando doutrina e legislação brasileiras, podem-se encontrar alguns mecanismos capazes de, de certa forma, proverem o fármaco aos portadores de doenças raras.

\subsubsection{Do licenciamento compulsório}

O direito de propriedade confere ao seu titular a exploração com exclusividade do objeto da patente. No entanto, quando o titular deixa de atender à função social, como ocorre quando deixa de fabricar medicamentos, o Estado poderá intervir em seu direito de propriedade através do licenciamento compulsório. Licenciamento compulsório se dá pela ocorrência de exercício abusivo dos direitos decorrentes da patente, nos casos de emergência nacional ou interesse público, de abuso do poder econômico, da dependência da patente, de inexploração ou exploração precária do objeto da patente em território brasileiro, assim como pela comercialização que não atenda as necessidades de mercado. ${ }^{25} \mathrm{~A}$ concessão do direito de patente confere ao titular a possibilidade de exploração exclusiva do bem objeto da propriedade industrial. No entanto, para que este direito não se apresente de forma inútil e desprovida de função social à sociedade, o titular ou terceiro licenciado deverá cumprir com alguns deveres, dentre eles a exploração do bem. ${ }^{26}$ Quando as obrigações inerentes à função social da propriedade, inclusive a exploração, não forem atendidas pelo titular da patente, poderá haver a intervenção estatal, que poderá valer-se do instituto do licenciamento compulsório para impor que a utilização do bem se dê de acordo com sua função social. Ao licenciamento também se denomina de quebra de patentes, pois representa uma ruptura da relação jurídica existente entre titular, bem material e sociedade. ${ }^{27}$

A quebra de patentes deve possuir prazo determinado, restrito ao objeto para o qual foi autorizada. Não pode ser exclusiva, ou seja, não é garantido ao licenciado,

\footnotetext{
25 BARROS, Carla Eugênia Caldas. Manual de Direito da Propriedade Industrial. Aracajú: Evocati, 2007. p. 276.

26 BEZERRA, Matheus Ferreira. Patente de Medicamentos: quebra de patente como instrumento de realização do direito. p. 112.

27 BEZERRA, Matheus Ferreira. Patente de Medicamentos: quebra de patente como instrumento de realização do direito. p. 114-115.
} 
autorizado a fabricar o bem, que irá fazê-lo de forma exclusiva, pois o titular da patente poderá seguir fabricando, diretamente ou através da concessão de licenças voluntárias para outros interessados. ${ }^{28}$ Uma vez realizada a quebra da patente dos medicamentos, terceiros poderão explorá-la sem exclusividade, aumentando a oferta e, consequentemente, promovendo a livre concorrência. Para isso, basta que o interessado apresente requerimento demonstrando que possui condições de promover a fabricação do produto.

Em relação à propriedade industrial dos medicamentos, a finalidade social destina-se à promoção da saúde, seja ela pública ou individual, já que se destinam ao auxílio de tratamento médico. Dessa forma, com a necessidade de utilização de determinado medicamento, a patente destes fármacos poderá se inserir no conflito entre interesses econômicos e interesses sociais. ${ }^{29}$ Nesse sentido, no caso em que a propriedade industrial do medicamento esteja servindo apenas a interesses econômicos, impedindo o seu acesso à população e, assim, comprometendo sua saúde, poderá haver a intervenção estatal licenciando aquela propriedade imaterial.

Sendo assim, quando a produção e a distribuição de produtos farmacêuticos não atendam devidamente à defesa da saúde, deverá o Estado intervir, restabelecendo a ordem jurídica e a função social da propriedade dos medicamentos, através de medidas existentes no ordenamento jurídico. O Poder Público possui várias formas de atuação sobre os produtos farmacêuticos referentes ao consumo como a fiscalização, o controle de vendas, o controle de preços e o abastecimento do mercado interno. Entretanto, a medida mais efetiva e de maior repercussão para a saúde pública é o licenciamento compulsório, pois incide sobre todo o processo produtivo até o consumo. ${ }^{30}$

Cabe ressaltar que a licença compulsória somente será concedida se o requerente tiver buscado antes e diretamente autorização do titular da patente que, no caso dos medicamentos, é o laboratório farmacêutico. Exceções a esta exigência são os casos em que houver emergência nacional ou outras circunstâncias de extrema urgência ou, ainda, de uso público não comercial. Exemplo de licenciamento compulsório decretado pelo Poder Público, concedido por interesse público, é o caso da quebra de patentes dos antirretrovirais para atender aos portadores do HIV. ${ }^{31}$

\footnotetext{
28 GRANGEIRO, Alexandre et al. Propriedade Intelectual, Patentes \& Acesso Universal a Medicamentos. São Paulo: Grupo de Incentivo à Vida/Grupo pela Vidda-SP/Centro de Referência e Treinamento em DST/AIDS de São Paulo/Instituto de Saúde, 2006. p. 19.

29 BEZERRA, Matheus Ferreira. Patente de Medicamentos: quebra de patente como instrumento de realização do direito. p. 146.

30 BEZERRA, Matheus Ferreira. Patente de Medicamentos: quebra de patente como instrumento de realização do direito. p. 147.

31 BENETTI, Daniela Vanila Nakalski. Positivação e (in)eficácia da licença compulsória frente ao "novo bilateralismo" comercial. In: ADOLFO, Luiz Gonzaga Silva; MORAES, Rodrigo (Coord.). Propriedade Intelectual em Perspectiva. Rio de Janeiro: Lumen Juris, 2008. p. 23-24.
} 
A licença compulsória deve ser utilizada, com atenção ao Trips e à lei nacional, sempre que necessária, levando em consideração a proibição de excesso e a proibição de insuficiência no equilíbrio dos direitos envolvidos. Da mesma forma, a quebra de patentes não deve transformar-se em política pública. Deve servir como elemento de controle e de equilíbrio que possibilite a concretização do direito à saúde, inclusive do acesso aos medicamentos. ${ }^{32}$

A intervenção do Estado na propriedade imaterial dos medicamentos, licenciando-a compulsoriamente somente poderá ocorrer nas hipóteses autorizadas expressamente pela Lei no 9.279/96 em seus arts. 68, ${ }^{33} 70^{34}$ e $71 .{ }^{35}$ Assim, a quebra de patentes poderá ocorrer sempre que se caracterizar: a) casos de emergência nacional ou interesse público; b) abuso de poder econômico; c) situação de dependência da patente. Contudo, o 1ำ36 $^{\text {on }}$ art. 68 do mesmo diploma legal também prevê duas outras razões para o licenciamento compulsório: a inexploração total ou parcial do bem objeto da patente no território brasileiro, seja na fabricação do produto, seja quanto ao uso de processo, salvo em situações de inviabilidade econômica, admitindo-se, no caso, a importação. A falta de fabricação de produtos farmacêuticos, como se pode perceber, enquadra-se na hipótese de abuso do poder econômico, mais especificamente, no §1ํㅡㄴ e, por este motivo, será o único analisado aqui.

\subsubsection{Licenciamento compulsório por abuso de poder econômico}

A quebra de patentes por abuso de poder econômico está prevista no art. $68^{37}$ da Lei no 9.279/96. O titular que exercer abusivamente seu direito de patente ou por meio da patente praticar abuso do poder econômico poderá ter seu direito

32 VIZZOTTO, Alberto. A Função Social das Patentes sobre Medicamentos. São Paulo: LCTE, 2010. p. 113.

33 Art. 68. O titular ficará sujeito a ter a patente licenciada compulsoriamente se exercer os direitos dela decorrentes de forma abusiva, ou por meio dela praticar abuso de poder econômico, comprovado nos termos da lei, por decisão administrativa ou judicial.

34 Art. 70. A licença compulsória será ainda concedida quando, cumulativamente, se verificarem as seguintes hipóteses: I - ficar caracterizada situação de dependência de uma patente em relação a outra;

II - o objeto da patente dependente constituir substancial progresso técnico em relação à patente anterior; e III - o titular não realizar acordo com o titular da patente dependente para exploração da patente anterior.

35 Art. 71. Nos casos de emergência nacional ou interesse público, declarados em ato do Poder Executivo Federal, desde que o titular da patente ou seu licenciado não atenda a essa necessidade, poderá ser concedida, de ofício, licença compulsória, temporária e não exclusiva, para a exploração da patente, sem prejuízo dos direitos do respectivo titular.

36 §1ํㅡㄹ Ensejam, igualmente, licença compulsória:

I - a não exploração do objeto da patente no território brasileiro por falta de fabricação ou fabricação incompleta do produto, ou, ainda, a falta de uso integral do processo patenteado, ressalvados os casos de inviabilidade econômica, quando será admitida a importação; ou

II - a comercialização que não satisfizer às necessidades do mercado.

37 Art. 68. O titular ficará sujeito a ter a patente licenciada compulsoriamente se exercer os direitos dela decorrentes de forma abusiva, ou por meio dela praticar abuso de poder econômico, comprovado nos termos da lei, por decisão administrativa ou judicial. 
licenciado compulsoriamente por via judicial ou administrativa. Aqui o Estado intervém em defesa do uso racional e ordenado da propriedade imaterial.

Quando se trata de medicamentos, esta licença compulsória "objetiva resguardar a saúde e nutrição públicas, bem como o comércio, nos casos em que a patente estiver sendo utilizada pelo seu titular de forma indevida e abusiva". ${ }^{38}$ Esta utilização abusiva e contrária aos preceitos constitucionais, quando se trata dos fármacos, poderá ocorrer de forma indireta ou direta.

No primeiro caso, ou seja, de forma indireta, o abuso ocorre na distribuição dos medicamentos pelos comerciantes, impedindo a livre concorrência e ocasionando o aumento dos preços. 0 Estado poderá intervir através do controle de abastecimento do mercado e de preços. Já quando a abusividade se der de maneira direta, ocorrendo abuso por negligência do titular na fase de produção do medicamento, sem motivo justo, poderá o Estado intervir diretamente na propriedade, determinando o licenciamento compulsório. ${ }^{39}$

Estes mecanismos adotados pelo Estado são necessários, pois protegem o próprio sistema capitalista de livre-mercado. Considerando a exclusividade conferida ao titular da patente, a análise do poder econômico torna-se ainda mais relevante, pois o ato abusivo praticado pelo produtor único causará muito mais danos à sociedade do que se houvesse vários produtores do mesmo bem.

Apesar do conceito aberto do abuso do poder econômico, o art. 36 da Lei no $12.529 / 2011^{40}$ apresenta algumas das atividades que caracterizam infração à ordem econômica, que não serão objeto específico desta investigação. Além disso, o próprio art. 68 , nos incisos I e II de seu $\S 1^{10},{ }^{41}$ tipificou duas condutas: a não exploração do bem e a exploração menor que a necessidade do mercado. Assim, o fato de 0 laboratório farmacêutico deixar de fabricar medicamento para doenças raras por serem pouco frequentes e trazerem pouco lucro caracteriza caso para o licenciamento compulsório por abuso do poder econômico pela inexploração do bem objeto da patente.

\subsubsection{Licenciamento compulsório pela não exploração da patente}

Ao contrário das outras hipóteses de quebra de patentes, que representam medidas para conter excessos do seu titular na utilização do bem ou para atender

38 DALLARI, Sueli Gandolfi; NUNES JÚNIOR, Vidal Serrano. Direito Sanitário. São Paulo: Verbatim, 2010. p. 182.

39 BEZERRA, Matheus Ferreira. Patente de Medicamentos: quebra de patente como instrumento de realização do direito. p. 152-153.

40 Lei que estrutura o sistema brasileiro de defesa da concorrência. Dispõe sobre prevenção e repressão às infrações contra a ordem econômica.

$41 \S 1^{\circ}$ Ensejam, igualmente, licença compulsória: I - a não exploração do objeto da patente no território brasileiro por falta de fabricação ou fabricação incompleta do produto, ou, ainda, a falta de uso integral do processo patenteado, ressalvados os casos de inviabilidade econômica, quando será admitida a importação; ou II - a comercialização que não satisfizer às necessidades do mercado. 
as necessidades da sociedade, diferentes ao direito de propriedade, o licenciamento compulsório pela não exploração consiste na falta de exploração do bem objeto da patente por seu titular. Nos demais casos de licença compulsória, o titular exerce seu direito de proprietário da patente e se mostra contrário ou aquém dos interesses da sociedade. Já no caso da quebra de patentes pela não exploração do bem, o objeto não é destinado às finalidades para as quais foi inventado e patenteado, como o desenvolvimento social, científico, tecnológico e, inclusive, a remuneração de seu titular. ${ }^{42}$

Conforme Bezerra, ${ }^{43}$ "a conduta do titular da patente em não exercer o seu direito de exploração sobre o bem pode ser encarada como o ponto máximo do abuso do direito de propriedade em relação à propriedade industrial".

A Constituição Federal, no inciso XXIX do art. 5ํㅡ, estabelece que a lei assegurará privilégio temporário aos autores de inventos industriais, tendo em vista o interesse social e o desenvolvimento tecnológico do país. Em análise ao preceito constitucional, pode-se perceber, há o condicionamento da proteção do direito à propriedade intelectual à utilização do objeto da patente. Assim, conforme $\S^{5044}$ do art. 68 da Lei no 9.279/96, não ocorrendo a exploração do bem objeto da patente após três anos da concessão da patente, poderá a propriedade intelectual ser objeto de licenciamento compulsório.

Devido à importância dos medicamentos, em não havendo interesse na produção pelo detentor da patente e ocorrendo quebra da patente não surgirem interessados na produção do medicamento, entende-se que o Estado deverá assumir, como licenciante, a produção do fármaco, através da produção de medicamento genérico ou providenciar para que o produto seja importado de outro país. 0 que não pode é o Poder Público ficar inerte, pois a falta de fabricação de um medicamento atinge a saúde e, muitas vezes, especialmente quando se refere às doenças raras, a vida dos pacientes.

É claro que, existindo justa causa para a não exploração do bem, este não será licenciado. ${ }^{45}$ Caberá ao Poder Público, analisando os argumentos apresentados pelo titular da patente sem exploração, decidir pela quebra da patente ou por fornecer os meios para que o bem venha a ser produzido e posto à disposição da população.

\footnotetext{
42 BEZERRA, Matheus Ferreira. Patente de Medicamentos: quebra de patente como instrumento de realização do direito. p. 159-159.

43 BEZERRA, Matheus Ferreira. Patente de Medicamentos: quebra de patente como instrumento de realização do direito. p. 158.

44 §5ํㅗ A licença compulsória de que trata o $\S 1^{\circ}$ somente será requerida após decorridos 3 (três) anos da concessão da patente.

45 Art. 69. A licença compulsória não será concedida se, à data do requerimento, o titular:

I - justificar o desuso por razões legítimas;

II - comprovar a realização de sérios e efetivos preparativos para a exploração; ou

III - justificar a falta de fabricação ou comercialização por obstáculo de ordem legal.
} 
No Brasil, a utilização da licença compulsória ainda é limitada, somente se consolidando quando não foi possível negociar com o titular da patente. Segundo Benetti, ${ }^{46}$ essa dificuldade de se utilizar do licenciamento compulsório deve-se a dois fatores. 0 primeiro deles refere-se ao temor dos Estados menos desenvolvidos de sofrerem retaliações dos Estados mais desenvolvidos. 0 segundo advém da incapacidade tecnológica dos países menos capacitados à produção de medicamentos.

Após análise da possibilidade de concessão do licenciamento compulsório pela inexploração da patente, pode-se perceber que resolve apenas problema específico, inclusive no caso dos medicamentos, pois apenas um medicamento pode ter sua patente quebrada por vez. Porém, não contribui para sanar a insuficiência da indústria nacional, pois não fomenta o desenvolvimento do setor farmacêutico no país. ${ }^{47}$ Assim, essa possibilidade de licenciar compulsoriamente o direito de propriedade industrial não resolve o problema concernente aos fármacos destinados às doenças raras. Se utilizado o licenciamento pelo Poder Público, resolverá o problema apenas de um medicamento órfão de cada vez. Percebe-se, dessa forma, a necessidade de uma política pública específica voltada para estes medicamentos.

\subsubsection{Da importação paralela}

A atribuição de direitos de propriedade industrial é manifestação da soberania de cada Estado. Sendo assim, cabe a cada Estado determinar quais e como se constituem estes direitos, concedendo a respectiva proteção através de normas em nível nacional. No entanto, a proteção de determinado direito pode não ser reconhecida pelo ordenamento jurídico de outros países, a esta ideia encontra-se subjacente o regime da territorialidade. Segundo este regime, os direitos concedidos por diferentes ordenamentos, ainda que protejam o mesmo objeto, são direitos distintos sujeitos a diferentes proteções. Estes direitos de propriedade industrial conferidos por cada Estado poderão ser utilizados para bloquear a importação de produtos para os quais existe direito de exclusividade no país de destino. ${ }^{48}$

A importação paralela consiste na aquisição do produto patenteado no mercado estrangeiro, onde se encontra explorado por quem de direito. ${ }^{49}$ Ao invés de

46 BENETTI, Daniela Vanila Nakalski. Positivação e (in)eficácia da licença compulsória frente ao "novo bilateralismo" comercial. In: ADOLFO, Luiz Gonzaga Silva; MORAES, Rodrigo (Coord.). Propriedade Intelectual em Perspectiva. Rio de Janeiro: Lumen Juris, 2008. p. 30.

47 CARVALHO, Patrícia Luciane de. Patentes Farmacêuticas e Acesso a Medicamentos. São Paulo: Atlas, 2007. p. $174-175$

48 MAGALHÃES, Carina da Conceição Carvalho. A Patenteabilidade da Indústria Farmacêutica: O Interesse Público na Protecção da Saúde. Dissertação (Mestrado). Programa de Pós-Graduação em Direito. Universidade de Porto. Porto, 2012. Disponível em: <http://repositorio-aberto.up.pt/bitstream/10216/63873/2/Tese\%20 \%20Carina\%20Magalhes.pdf>. Acesso em: 20 jan. 2012. p. 153-154.

49 BEZERRA, Matheus Ferreira. Patente de Medicamentos: quebra de patente como instrumento de realização do direito. p. 118-119. 
comprar do representante local da empresa, a aquisição é feita com a empresa de outro país, onde o preço seja menor..$^{50}$ As importações paralelas tratam de produtos comercializados pelo titular da patente em um país e importados em outro país, sem a aprovação deste titular. ${ }^{51}$

Entretanto, sempre que o produto, neste caso o medicamento, seja direito privativo de propriedade industrial, a exportação do local onde é comercializado pode confrontar-se com direito de patente protegido no local da importação. Haverá violação desse direito de propriedade industrial quando os medicamentos forem exportados para países onde a venda não foi originalmente autorizada. ${ }^{52}$

Segundo Carvalho, ${ }^{53}$ é objetivo da importação paralela o acesso a medicamentos mais baratos ou não comercializados em um determinado local. Tais objetivos encontram-se vinculados ao uso necessário de medicamentos. Para que se possa analisar sistemicamente, deve-se considerar o art. 27.1 do Trips, o qual estabelece a disponibilidade das patentes farmacêuticas e que os direitos inerentes à propriedade intelectual devem ser usufruídos sem discriminação quanto ao local da invenção, ao teor tecnológico ou quanto ao fato de os bens serem importados ou produzidos localmente.

Desta análise, observa-se que o Trips fundamenta-se no regime da exaustão internacional dos direitos de propriedade industrial. Em razão disso, um terceiro país sem autorização pode importar o fármaco de outro país que já o importa com autorização. Carvalho, ${ }^{54}$ tratando especificamente acerca das patentes de medicamentos, explica que o sistema de exaustão internacional é complementado pela importação paralela de um fármaco patenteado que seja vendido por menor preço em outros países. Assim, sendo negada a exaustão internacional às patentes de medicamentos, nega-se também regra do Trips.

É a escolha do sistema de exaustão ${ }^{55}$ que viabilizará ou proibirá a prática da importação paralela. Constitui-se, portanto, em escolha política voltada à proteção

50 GRANGEIRO, Alexandre et al. Propriedade Intelectual, Patentes \& Acesso Universal a Medicamentos. São Paulo: Grupo de Incentivo à Vida/Grupo pela Vidda-SP/Centro de Referência e Treinamento em DST/AIDS de São Paulo/Instituto de Saúde, 2006. p. 19.

51 MUÑOZ, Silvia Valverde. Los derechos de propiedad intelectual y el acceso a los medicamentos, a nivel mundial. In: VELA, Rafael Barranco; SÁENZ, Francisco Miguel Bombillar. El Acceso al Medicamento: retos jurídicos actuales, intervención pública y su vinculación al derecho a la salud. Granada: Editorial Comares, 2010. p. 97.

52 MAGALHÃES, Carina da Conceição Carvalho. A Patenteabilidade da Indústria Farmacêutica: o Interesse Público na Protecção da Saúde. Dissertação (Mestrado). Programa de Pós-Graduação em Direito. Universidade de Porto. Porto, 2012. Disponível em: <http://repositorio-aberto.up.pt/bitstream/10216/63873/2/Tese\%20 \%20Carina\%20Magalhes.pdf>. Acesso em: 20 jan. 2012. p. 155.

53 CARVALHO, Patrícia Luciane de. Patentes Farmacêuticas e Acesso a Medicamentos. São Paulo: Atlas, 2007. p. 64.

54 CARVAlHO, Patrícia Luciane de. Patentes Farmacêuticas e Acesso a Medicamentos. São Paulo: Atlas, 2007. p. 65.

55 Existe amplo e complexo debate acerca das implicações econômicas e sociais dos regimes de exaustão de direitos. A conclusão sobre qual o melhor regime a ser aplicado não serve para todos os tipos de propriedade intelectual. Para aprofundamento desta questão: BASSO, Maristela. Implicações econômicas e sociais da importação paralela no comércio internacional e nos direitos de propriedade intelectual. In: TIMM, Luciano Benetti; BRAGA, Rodrigo Bernardes (Org.). Propriedade Intelectual. Belo Horizonte: Arraes Editores, 2011. p. 111-122. 
da indústria nacional ou à competição entre os produtos ofertados ao mercado internacional. ${ }^{56}$ Pelo sistema de exaustão nacional, o direito de exclusividade vai cessar quando ocorrer a primeira venda no mercado nacional importador, podendo impedir importação por outros países sem autorização. Se se tratar, no entanto, do sistema de exaustão internacional, cessa a exclusividade com a venda em qualquer país, permitindo, assim, a importação paralela. ${ }^{57}$

O Brasil optou pelo sistema da exaustão nacional, onde o titular da patente pode opor-se à importação de seu produto quando oriundo de outro país. ${ }^{58}$ Nesse sentido, os arts. $183^{59}$ e $184^{60}$ da Lei no 9.279/96 instituíram como crime as condutas de fabricar, comercializar, manter em estoque ou a utilização para fins lucrativos do produto patenteado. A partir da interpretação dessas normas, percebe-se que se encontra vedada a importação paralela, ou seja, a importação do bem patenteado que não tenha sido colocado no mercado externo pelo titular da patente ou por terceiro autorizado. Entretanto, em algumas situações excepcionais, comprovadas por seu titular, poderá ser admitida, sob pena de ser compelido a conceder a licença compulsoriamente. Isso ocorrerá quando houver impossibilidade econômica da produção do bem num determinado país em que a proteção fora concedida. ${ }^{61}$

A Lei no 9.279, nos §§కº e 4ำ2 do art. 68, prevê hipóteses de permissão da importação paralela, excluindo a ilicitude do art. 184, em duas hipóteses: em

56 BEZERRA, Matheus Ferreira. Patente de Medicamentos: quebra de patente como instrumento de realização do direito. p. 119.

57 CARVALHO, Patrícia Luciane de. Patentes Farmacêuticas e Acesso a Medicamentos. São Paulo: Atlas, 2007. p. 64.

58 BEZERRA, Matheus Ferreira. Patente de Medicamentos: quebra de patente como instrumento de realização do direito. p. 119.

59 Art. 183. Comete crime contra patente de invenção ou de modelo de utilidade quem:

I - fabrica produto que seja objeto de patente de invenção ou de modelo de utilidade, sem autorização do titular; ou

II - usa meio ou processo que seja objeto de patente de invenção, sem autorização do titular. Pena - detenção, de 3 (três) meses a 1 (um) ano, ou multa.

60 Art. 184. Comete crime contra patente de invenção ou de modelo de utilidade quem:

I - exporta, vende, expõe ou oferece à venda, tem em estoque, oculta ou recebe, para utilização com fins econômicos, produto fabricado com violação de patente de invenção ou de modelo de utilidade, ou obtido por meio ou processo patenteado; ou

II - importa produto que seja objeto de patente de invenção ou de modelo de utilidade ou obtido por meio ou processo patenteado no País, para os fins previstos no inciso anterior, e que não tenha sido colocado no mercado externo diretamente pelo titular da patente ou com seu consentimento. Pena - detenção, de 1 (um) a 3 (três) meses, ou multa.

61 BEZERRA, Matheus Ferreira. Patente de Medicamentos: quebra de patente como instrumento de realização do direito. p. 111.

62 §3ํำ No caso de a licença compulsória ser concedida em razão de abuso de poder econômico, ao licenciado, que propõe fabricação local, será garantido um prazo, limitado ao estabelecido no art. 74, para proceder à importação do objeto da licença, desde que tenha sido colocado no mercado diretamente pelo titular ou com o seu consentimento.

§4 № caso de importação para exploração de patente e no caso da importação prevista no parágrafo anterior, será igualmente admitida a importação por terceiros de produto fabricado de acordo com patente de processo ou de produto, desde que tenha sido colocado no mercado diretamente pelo titular ou com o seu consentimento. 
caso de concessão de licenciamento compulsório por abuso do poder econômico, o licenciado poderá, pelo prazo de até um ano, importar o objeto da licença, desde que tenha sido posto no mercado por seu titular ou com o seu consentimento; e no caso de importação para exploração da patente ou no caso da importação em virtude de licenciamento compulsório por abuso do poder econômico, será admitida a importação por terceiro(s) do produto fabricado de acordo com patente de processo ou de produto, contanto que tenha sido colocado no mercado pelo titular da patente ou com seu consentimento.

A importação paralela é muito importante para suprir as falhas dos laboratórios e indústrias farmacêuticas em atender às necessidades de mercado, já que o abuso do poder econômico compromete o acesso aos medicamentos. Além disso, tem fundamental importância para a sustentabilidade de políticas nacionais na área da saúde pública, pois possibilita a aquisição de medicamentos mais baratos. Isso porque há muita variação de preços de fármacos de um país para outro, muitas vezes mostrando-se abusivo o preço praticado no mercado interno. ${ }^{63}$

0 Trips, a fim de tornar efetivo o licenciamento compulsório para proteção da saúde pública, regulamentou o seu parágrafo 6으, permitindo que os Estados que, como o Brasil, possuem menor, insuficiente ou inexistente potencial de fabricação de medicamentos, possam realizar importações paralelas. Permite o Trips a importação paralela de medicamentos que sejam vendidos em outros países por preço mais favorável.

Assim, constatando-se a insuficiência ou a falta de medicamentos no mercado interno, o Estado ou terceiro interessado estarão autorizados, pelo prazo de um ano, a adquirirem produtos licenciados até que se inicie ou se torne suficiente a produção do fármaco patenteado para atender às necessidades da população.

Foi o que aconteceu, em 2007, com a primeira decretação de quebra de patentes do medicamento, ${ }^{64}$ para portadores do vírus HIV, onde foi feita a importação paralela da versão genérica do antirretroviral Efavirenz.

Os procedimentos para a adoção da licença compulsória, via importação paraIela, são complexos. Isso porque devem ser realizados para cada medicamento e em cada Estado que for licenciado. Além do mais, é difícil ocorrer a exportação do produto em larga escala sem incentivo à fabricação de genéricos e não haverá redução de preços dos medicamentos mais recentes sem concorrência. Na perspectiva da

\footnotetext{
63 BEZERRA, Matheus Ferreira. Patente de Medicamentos: quebra de patente como instrumento de realização do direito. p. 175.

64 O Decreto n 6.107/2007 que autorizou a referida licença compulsória dispôs em seu art. 5 que “caso não seja possível o atendimento à situação de interesse público com o produto colocado no mercado interno, ou se mostre inviável a fabricação, no todo ou em parte, dos objetos das patentes pela União ou por terceiros contratados ou conveniados, poderá a União realizar a importação do produto objeto das patentes, sem prejuízo da remuneração prevista no art. $2^{2} "$.
} 
Organização Médicos Sem Fronteiras, o licenciamento compulsório via OMC fracassou, já que não provou o aumento do acesso aos medicamentos pelos Estados menos desenvolvidos ou sem produção farmacêutica. ${ }^{65}$

No Brasil somente ocorreu o licenciamento compulsório do medicamento para HIV, ocorrendo após a importação paralela. Percebe-se, desse modo, que pouco foi utilizado e apenas para os portadores da AIDS aumentou o acesso aos medicamentos necessários à manutenção de sua saúde e de suas vidas. Ocorreram, na verdade, outras ameaças de quebra de patentes contra os laboratórios farmacêuticos para redução de preços. Nos mandatos dos Presidentes Fernando Henrique Cardoso e Luiz Inácio Lula da Silva determinados antirretrovirais foram declarados como de interesse público para a concessão da licença, porém, após negociação entre o Poder Público e os laboratórios farmacêuticos, ficou acordada a redução de preços e não houve a quebra de patentes. Pode-se citar como exemplo o ocorrido no ano de 2001, quando o atual Ministro da Saúde José Serra declarou o licenciamento compulsório da patente do Nelfinavir do laboratório Roche. Foram nove meses de negociações e, no dia em que foi declarada a quebra da patente, o laboratório reduziu os preços em $40 \%$ de acordo com o que exigia a Administração Pública. Da mesma forma, em 2005, quando o Ministro da Saúde Humberto Costa e o Presidente Luiz Inácio declararam o interesse público do antirretroviral Kaletra, produzido pelo laboratório Abbott. Entretanto, após negociações, ocorreu a redução do preço do medicamento por um período de seis anos e, através de licença voluntária, o laboratório concedeu ao país o acesso à nova fórmula do Kaletra e interferiu na tecnologia da formulação do Lopinavir e do Ritonavir. 0 acordo resultou na economia de US\$339,5 milhões nos anos de 2006 a 2009. ${ }^{66}$

Pode-se constatar, portanto, que este instituto da importação paralela também não resolve o problema do fornecimento de medicamentos aos portadores de doenças raras pois, quando utilizado, assim como no caso do licenciamento compulsório, apenas resolve a falta de um medicamento por vez.

\subsection{Breve análise da política pública de medicamentos para doenças raras nos Estados Unidos e na União Europeia}

A primeira legislação sobre medicamentos órfãos foi introduzida nos EUA em 1983. Outros países como a Austrália, Japão e Singapura também o fizeram na

\footnotetext{
65 Médicos Sem Fronteira. A Nova Crise de Acesso a Medicamentos Anti-Aids: preços de anti-retrovirais financeiramente inviáveis... novamente. Disponível em: <www.deolhonaspatentes.com.br>. Acesso em: 29 nov. 2012.

66 BENETTI, Daniela Vanila Nakalski. Positivação e (in)eficácia da licença compulsória frente ao "novo bilateralismo" comercial. In: ADOLFO, Luiz Gonzaga Silva; MORAES, Rodrigo (Coord.). Propriedade Intelectual em Perspectiva. Rio de Janeiro: Lumen Juris, 2008. p. 24-25.
} 
década de 1990. Em 2000, a União Europeia estabeleceu sua própria legislação. Os métodos utilizados para estimular a pesquisa e o desenvolvimento dos medicamentos órfãos são similares, com pequenas diferenciações ${ }^{67}$ Será objeto de análise a política de medicamentos para doenças raras nos Estados Unidos e na Comunidade Europeia.

\subsubsection{Política pública de medicamentos para doenças raras nos Estados Unidos}

Entre a década de 1950 e o início da década de 1980, houve, nos Estados Unidos, ativismo em defesa dos portadores de doenças raras. Este fato chamou a atenção da opinião pública para os problemas de financiamento e desenvolvimento de tecnologias relacionadas às doenças raras. Grupos buscaram estabelecer uma colaboração formal entre diversas entidades, originando um elo entre cientistas e pacientes. Isso possibilitou o desenvolvimento de entidades capazes de captar recursos para pesquisa, ensaios clínicos e início de testes em drogas inovadoras para o tratamento das doenças raras. Tal processo culminou com a instituição da Orphan Drug Act (ODA) em 1983, legislação específica para regular o desenvolvimento e o acesso da população aos medicamentos destinados ao tratamento de doenças raras. A ODA instituiu também diferentes formas de incentivo para o desenvolvimento de pesquisas e promoção de novos medicamentos para estas doenças. ${ }^{68}$

A Orphan Drug Act estabelece um procedimento centralizado de análise destes medicamentos, estabelecendo um canal direto de acesso à agência de regulação, com a designação, no menor tempo possível, do referido medicamento como órfão e, até mesmo, a autorização para sua comercialização. A lei também assegura a assistência a protocolos. Normalmente, o procedimento de aprovação de uma nova droga é demorado, pois são necessários vários tipos de testes que garantam sua qualidade, segurança e eficácia. Aqui, a indústria farmacêutica pode solicitar orientação da agência reguladora na condução destes testes. A agência reguladora desenvolve processos padronizados que comprovam o funcionamento seguro do fármaco no menor tempo possível. ${ }^{69}$

Em 1985, a ODA foi emendada para ampliar a exclusividade para produtos patenteáveis e não patenteáveis. Assim, quando um medicamento é designado como

67 STOLK, Pieter; WILLEMEN, Marjolein J. C.; LEUFKENS, Hubert G.N. "Rare Essencials": drugs for rare as essencial medicines. Bulletin of the World Health Organization, n. 84, p. 746, 2006.

68 WIEST, Ramon. A Economia das Doenças Raras: teorias, evidências e políticas públicas. Monografia. Departamento de Ciências Econômicas. Faculdade de Ciências Econômicas da Universidade Federal do Rio Grande do Sul. Porto Alegre, 2010. p. 58-59.

69 WIEST, Ramon. A Economia das Doenças Raras: teorias, evidências e políticas públicas. Monografia. Departamento de Ciências Econômicas. Faculdade de Ciências Econômicas da Universidade Federal do Rio Grande do Sul. Porto Alegre, 2010. p. 63-64. 
órfão, o seu fabricante terá direito de exclusividade de comercialização pelo prazo de sete anos..$^{70} \mathrm{O}$ objetivo foi o de proteger aqueles produtos que seriam patenteáveis, mas cujas patentes expirariam antes ou logo em seguida à aprovação para o mercado. ${ }^{71}$ Essa exclusividade é o incentivo mais importante nos Estados Unidos, conforme o Department of Health and Human Services, pois impõe uma limitação à competição. Isso porque proíbe a aprovação de outro medicamento para o mesmo fim, exceto se o novo for superior em qualidade ao primeiro. ${ }^{72}$

Segundo Seoane-Vázquez et al., ${ }^{73}$ a exclusividade não compartilha o mesmo nivel de proteção da patente. Durante o período de exclusividade de mercado, o FDA (Federal Drug Administration) não pode aprovar um NDA (New Drog Application) ou uma droga genérica para o mesmo produto e para a mesma doença rara. 0 FDA poderá, no entanto, aprovar uma segunda aplicação para o mesmo medicamento para uma segunda doença.

Em 1988 houve outra mudança, a aplicação da designação de medicamento órfão passou a ter prioridade quando submetida à aprovação de mercado. ${ }^{74}$

Nos Estados Unidos há o Fundo de Financiamento de Pesquisa, administrado pelo governo e por instituições não governamentais com o fim específico de financiar medicamentos órfãos. Além disso, há incentivos de isenção tributária e redução de taxas. A renúncia às taxas é aplicada, sem restrição, em todos os casos que envolvam medicamentos para doenças órfãs. A isenção tributária é aplicada como crédito de tributos na ordem de cinquenta por cento para os custos com o desenvolvimento de uma nova droga no país. ${ }^{75}$

Existe também o programa de subsídios para os medicamentos órfãos. Esse programa garante suporte financeiro para testes clínicos para determinar a segurança e a eficácia dos produtos para combater ou diagnosticar distúrbios raros. ${ }^{76}$

O impacto da lei de medicamentos para doenças raras nos EUA foi analisado em 2003. Após a introdução da legislação cerca de 1.100 medicamentos foram designados

70 HAFFNER, Marlene E. The United States Orphan Drug Act: challenges and success. Drug Information Jornal, v. 31, p. 24, 1997.

71 KATARIA, Mahesh Kumar et al. An Insight on Regulations Governing Orphan Diseases and Drugs. Research Journal of Pharmaceutical Biological and Chemical Sciences, v. 2, p. 377, Jul./Set. 2011.

72 WIEST, Ramon. A Economia das Doenças Raras: teorias, evidências e políticas públicas. Monografia. Departamento de Ciências Econômicas. Faculdade de Ciências Econômicas da Universidade Federal do Rio Grande do Sul. Porto Alegre, 2010. p. 64.

73 SEOANE-VAZQUÉZ, Enrique et al. Incentives for Orphan Drug Research and Development in the United States. Orphanet Journal of Rare Diseases, 2008. Disponivel em: <http//www.ojrd.com/content/3/1/33>. Acesso em: 24 fev. 2012. p. 02.

74 KATARIA et al. An Insight on Regulations Governing Orphan Diseases and Drugs. Research Journal of Pharmaceutical Biological and Chemical Sciences, v. 2, p. 377, Jul./Set. 2011.

75 WIEST, Ramon. A Economia das Doenças Raras: teorias, evidências e políticas públicas. Monografia. Departamento de Ciências Econômicas. Faculdade de Ciências Econômicas da Universidade Federal do Rio Grande do Sul. Porto Alegre, 2010. p. 64.

76 HAFFNER, Marlene E. The United States Orphan Drug Act: challenges and success. Drug Information Journal, v. 31, p. 25, 1997. 
como órfãos. Destes, 231 foram colocados no mercado, acarretando estimados 11 milhões de pacientes com novo tratamento para sua doença. ${ }^{77}$ Percebe-se, desse modo, que apesar de não solucionar totalmente o problema com o tratamento e medicamentos para doenças raras, a instituição de uma política pública pode levar ao tratamento de grande número de pacientes e, com isso, salvar muitas vidas.

\subsubsection{Política pública de medicamentos para doenças raras na União Europeia}

Em abril de 2000 na Comunidade Europeia entrou em vigor Regulamento (CE) $141 / 2000$ e o Regulation on Orphan Medical Products (847/2000) regrando a produção e o mercado de medicamentos para doenças raras. A partir destes regulamentos, a União Europeia adotou regime próprio de incentivos ao desenvolvimento de medicamentos para doenças raras, evitando que seus Estados-membros adotassem outras medidas que pudessem provocar distorções de competência e obstáculos aos intercâmbios comunitários. Por estes regulamentos, é necessário, na União Europeia, que o órgão que desenvolve o medicamento comprove que ele é destinado ao diagnóstico, prevenção ou tratamento de doença rara. Comprovando, inclusive, que não existe ainda fármaco com esta finalidade ou que, se já houver, o novo medicamento é mais eficaz do que o já existente. ${ }^{78}$

O Regulamento o 141/2000 criou um procedimento comunitário, aberto e transparente para designar os medicamentos órfãos, além de estabelecer incentivos à investigação, desenvolvimento e comercialização destes medicamentos. Isso se fez, principalmente, com a concessão de direito de exclusividade comercial de dez anos de duração.

Na Comunidade Europeia há procedimento centralizado para a autorização de comercialização destes medicamentos desde 2005. Este procedimento centralizado traz importante economia procedimental, pois se submete o medicamento a apenas um processo de avaliação, evitando que os laboratórios farmacêuticos tenham que pedir autorização para o produto em cada Estado. Isso ajuda o mercado interno de medicamentos, assim como protege a saúde pública. ${ }^{79}$

\footnotetext{
77 STOLK, Pieter; WILLEMEN, Marjolein J. C.; LEUFKENS, Hubert G. N. "Rare Essencials": drugs for rare as essencial medicines. Bulletin of the World Health Organization, n. 84, p. 747, 2006.

78 WIEST, Ramon. A Economia das Doenças Raras: teorias, evidências e políticas públicas. Monografia. Departamento de Ciências Econômicas. Faculdade de Ciências Econômicas da Universidade Federal do Rio Grande do Sul. Porto Alegre, 2010. p. 58-59.

79 VELA, Rafaela Barranco. El Estatuto Jurídico de los medicamentos huérfanos em la Unión Europea: el derecho de la salud de los pacientes com enfermidades raras. In: VELA, Rafael Barranco; SÁENZ, Francisco Miguel Bombillar (Org.). El Acceso al Medicamento: retos jurídicos actuales, intervención pública y su vinculación al derecho de la salud. Granada: Editorial Comares, 2010. p. 122.
} 
Cabe ressaltar que os medicamentos órfãos constituem cerca de $15 \%$ das autorizações centrais da União Europeia. ${ }^{80}$ Para facilitar ou manter a concessão da autorização de comercialização dos medicamentos órfãos, existe a faculdade de concessão de uma isenção, ao menos parcial, das taxas devidas à EMEA pelo fabricante do medicamento órfão. As perdas que estas medidas possam acarretar serão indenizadas à EMEA através de uma contribuição especial anual dos países integrantes da Comunidade Europeia. Além disso, previamente à solicitação de autorização, o promotor de um medicamento órfão poderá requerer à EMEA assistência na elaboração de protocolo, ou seja, um ditame sobre os diversos ensaios e provas que deverão ser realizadas para demonstrar a qualidade, segurança e eficácia do fármaco. Isso beneficia as empresas farmacêuticas europeias no desenvolvimento de novos medicamentos, seu assessoramento científico e assistência técnica. ${ }^{81}$

Na União Europeia a questão tributária é tratada separadamente por cada país membro, sendo a política aplicada diferente em cada país. No entanto, a redução de taxas cobradas pela agência reguladora será implementada para todos os procedimentos centralizados diretamente na EMEA. Para estes casos, é prevista isenção total de taxas de assistência a protocolos e fiscalização para pré-autorização. As taxas de autorização de mercado e as anuais referentes à pós-autorização têm uma redução de cinquenta por cento para os medicamentos órfãos. ${ }^{82}$

No entanto, a medida mais importante adotada no Regulamento no 141/2000 é o benefício do direito de exclusividade por dez anos após a autorização. ${ }^{83}$ Neste prazo, a Comunidade Europeia não aceitará qualquer outra solicitação prévia de comercialização, de conceder uma autorização prévia de comercialização ou de atender nova solicitação de prorrogação de uma autorização prévia à comercialização existente em relação a medicamento similar para a mesma indicação terapêutica. Poder-se-ia pensar, todavia, que o direito de patente já outorgaria a um medicamento adequada proteção comercial, não sendo necessária esta exclusividade comercial atribuída aos medicamentos órfãos. No entanto, pode acontecer que o fármaco em questão não possa ser objeto de proteção patentária por não ser novo ou original ou, ainda, por tratar-se de substância natural difícil de patentear. Pode ocorrer ainda, que o direito

80 STOLK, Pieter; WILLEMEN, Marjolein J. C.; LEUFKENS, Hubert G. N. "Rare Essencials": drugs for rare as essencial medicines. Bulletin of the World Health Organization, n. 84, p. 745, 2006.

81 VELA, Rafaela Barranco. El Estatuto Jurídico de los medicamentos huérfanos en la Unión Europea: el derecho de la salud de los pacientes com enfermidades raras. In: VELA, Rafael Barranco; SÁENZ, Francisco Miguel Bombillar (Org.). El Acceso al Medicamento: retos jurídicos actuales, intervención pública y su vinculación al derecho de la salud. Granada: Editorial Comares, 2010. p. 122-123.

82 WIEST, Ramon. A Economia das Doenças Raras: teorias, evidências e políticas públicas. Monografia. Departamento de Ciências Econômicas. Faculdade de Ciências Econômicas da Universidade Federal do Rio Grande do Sul. Porto Alegre, 2010. p. 64.

83 WEELY, S. van; LEUFKENS, H. G. M. Orphan Diseases: priority medicines for Europe and the world: "A public health approach to innovation". Background Paper, 2004. p. 04. 
sobre a propriedade intelectual já tenha expirado e somente após a expiração se tenha descoberto a aptidão do medicamento para tratar doença rara. ${ }^{84}$

O Regulamento ํo 507/2006 da Comunidade Europeia estabelece que para determinadas categorias de medicamentos pode ser necessário conceder autorizações de comercialização baseadas em dados clínicos menos completos que o habitual, nos quais não se encontra completamente documentada a inocuidade e eficácia do fármaco. Os medicamentos que se enquadram nesta categoria são aqueles destinados ao tratamento, prevenção ou diagnóstico de doenças gravemente debilitantes ou potencialmente mortais, àqueles destinados a situações de emergência e aos medicamentos órfãos. Estas autorizações com dados clínicos menos completos possuem como objetivo fomentar e possibilitar a chegada destes medicamentos ao mercado consumidor. Tais autorizações serão válidas por um ano, com possibilidade de renovação que deve ser requerida seis meses antes de expirada a autorização. Trata-se, assim, de autorização provisória e condicional até que se possa, após os dados clínicos que faltam, substituílla por uma autorização definitiva. ${ }^{85}$

Além destas medidas adotadas pela Comunidade Europeia em benefício do acesso aos medicamentos órfãos, alguns de seus países membros também regulam 0 acesso a estes medicamentos a pacientes com doença raras. ${ }^{86}$ Exemplo disso é a estratégia em doenças raras do Serviço Nacional de Saúde da Espanha, aprovada em junho de 2009. A França, no entanto, em 2005, foi o primeiro país a adotar um plano nacional para doenças raras. A França é o país europeu que dá mais destaque à questão das doenças raras. Objetiva, com seu plano nacional, disseminar o conhecimento, informações aos pacientes, treinamento profissional e promoção de pesquisa e desenvolvimento para tratamentos. Entre 2001 e 2008 instituiu 131 centros de referência em doenças raras, para facilitar diagnósticos e definir tratamentos, estabelecer protocolos, coordenar pesquisas e desenvolver programas para profissionais em saúde, pacientes e suas famílias. Há também uma política de triagem neonatal que identifica o acometimento por doença rara logo após o nascimento. Na verdade, todos os países europeus realizam esta triagem, sem exceção. ${ }^{87}$

84 VELA, Rafaela Barranco. El Estatuto Jurídico de los medicamentos huérfanos em la Unión Europea: el derecho de la salud de los pacientes com enfermidades raras. In: VELA, Rafael Barranco; SÁENZ, Francisco Miguel Bombillar (Org.). El Acceso al Medicamento: retos jurídicos actuales, intervención pública y su vinculación al derecho de la salud. Granada: Editorial Comares, 2010. p. 123.

85 VELA, Rafaela Barranco. El Estatuto Jurídico de los medicamentos huérfanos en la Unión Europea: el derecho de la salud de los pacientes com enfermidades raras. In: VELA, Rafael Barranco; SÁENZ, Francisco Miguel Bombillar (Org.). El Acceso al Medicamento: retos jurídicos actuales, intervención pública y su vinculación al derecho de la salud. Granada: Editorial Comares, 2010. p. 125-126.

86 Hughes et al. entendem, equivocadamente, que não há política de regulamentação para as doenças raras instituídas por seus países membros. In: HUGHES, D. A.; TUNNAGE, B.; YEO, S. T. Drugs for exceptionally rare diseases: do they deserve special status for funding?. Disponível em: <http://qjmed.oxfordjournals.org/>. Acesso em: 04 mar. 2012.

87 WIEST, Ramon. A Economia das Doenças Raras: teorias, evidências e políticas públicas. Monografia. Departamento de Ciências Econômicas. Faculdade de Ciências Econômicas da Universidade Federal do Rio Grande do Sul. Porto Alegre, 2010. p. 72. 
Também na União Europeia foi feita análise dos primeiros 5 anos da legislação pela EMEA. No geral a experiência foi positiva. Em abril de 2005, mais de 260 produtos adquiriram uma designação de medicamento órfão e 22 receberam autorização para colocação no mercado, gerando novas opções de tratamento para mais de um milhão de pacientes na Europa. ${ }^{88}$ Percebe-se, assim, que da mesma forma que nos Estados Unidos, na Comunidade Europeia a legislação para incentivo de pesquisa e tratamento de doenças raras também trouxe benefícios aos pacientes, principalmente no que se refere à produção de novos fármacos.

\subsection{Necessidade de uma política pública voltada aos medicamentos para doenças raras no Brasil}

No Brasil, a saúde é pública e de responsabilidade do Estado, ainda que a iniciativa privada possa explorá-la sob regulamento e fiscalização estatal. Isso porque, no país, a saúde é tema de política pública, seja ela preventiva ou incidental. ${ }^{89} \mathrm{O}$ conceito de política pública surgiu na Ciência Política e Administração Pública, mas atualmente encontra grande espaço na esfera jurídica. Segundo a Ciência Política, política pública "é a dimensão normativa ou moral do Estado, que perpassa a filosofia política ocidental e objetiva garantir uma vida feliz ao cidadão". A questão da política pública não se apresenta como algo isolado, pois deve dialogar com as esferas internacional, estatal e social e, por este motivo, ganha espaço no cenário jurídico..$^{90}$

Política pública é a conduta do Poder Executivo para a realização de programas e metas previstos em norma constitucional ou legal, sujeita ao controle jurisdicional no que se refere à eficiência dos meios empregados e à avaliação dos resultados alcançados. No Estado Social de Direito, a criação de uma lei significa a criação de um mero instrumento de governo, um princípio de condutas a serem implementadas e adimplidas, ciente das responsabilidades administrativas e políticas impostas ao Estado e seus agentes. A norma impõe ao Poder Público "a busca de meios idôneos para implementar efetivamente os objetivos estabelecidos" e a falta de implementação leva à responsabilização do Estado e de seus agentes. ${ }^{91} \mathrm{~A}$ situação é mais complicada onde o poder público permanece total ou parcialmente inerte como, por exemplo, no caso das doenças raras.

88 STOLK, Pieter; WILLEMEN, Marjolein J. C.; LEUFKENS, Hubert G.N. "Rare Essencials": drugs for rare as essencial medicines. Bulletin of the World Health Organization, n. 84, p. 747, 2006.

89 CARVALHO, Patrícia Luciane de. Patentes Farmacêuticas e Acesso a Medicamentos. São Paulo: Atlas, 2007. p. 19.

90 LIMBERGER, Têmis; SALDANHA, Jânia Maria Lopes. O direito à saúde e sua efetividade: o debate democrático perante o Supremo Tribunal Federal. Interesse Público, Belo Horizonte, ano 12, n. 64, p. 112, nov./dez. 2010.

91 KRELL, Andreas. Direitos Sociais e Controle Judicial no Brasil e na Alemanha. Porto Alegre: Sergio Antonio Fabris, 2002. p. 32. 
Cabe aqui ressaltar entendimento de Carvalho, ${ }^{92}$ quando explica que

Toda política pública deve, direta ou indiretamente, estar voltada para o cumprimento dos direitos fundamentais, os quais são essenciais, comuns a todos da sociedade. Além de serem comuns, percebe-se, com o transcorrer do tempo, que a ausência ou omissão na prestação de um direito fundamental causa a falência de uma série de outros direitos. É por esse motivo que o conceito de política pública encontra-se, irremediavelmente, vinculado ao de democracia.

O legislador está vinculado a conduzir o processo legislativo de acordo com os programas e fins estabelecidos pela Constituição Federal. Também o administrador deve governar o Estado no sentido de concretização dos ditames constitucionais, especialmente através de políticas públicas..$^{93}$

Uma constitucionalmente adequada política de medicamentos deve incentivar o desenvolvimento em investigação e desenvolvimento de novos medicamentos de elevada qualidade. Além disso, deve apresentar soluções que permitam o acesso generalizado aos medicamentos e eventualmente corrigindo, nas suas falhas, através de mecanismos de justiça social. ${ }^{94}$

Não há no Brasil uma política pública voltada para as doenças raras e para o fornecimento de medicamentos para seu tratamento. Como visto, existem alguns mecanismos (licenciamento compulsório, importação paralela e a produção de genéricos) que podem ser utilizados para proporcionar o acesso ao tratamento e medicamento aos pacientes. No entanto, tais mecanismos não são eficientes, pois são pouco utilizados e não são voltados especialmente às doenças raras. $E$, se fossem utilizados, resolveriam o fornecimento de um medicamento apenas, de cada vez. Fármacos destinados às doenças raras, por não oferecerem lucros, ficam relegados a segundo plano, pois não se encontram nas listas de prioridade dos laboratórios farmacêuticos que investem alto na produção de medicamentos que não estão diretamente ligados à saúde, como, por exemplo, aqueles fármacos que visam combater a queda de cabelos, o combate às rugas etc. Conforme Grau-Kuntz, ${ }^{95}$ o desenvolvimento de substâncias para o tratamento das doenças raras fica limitado às pesquisas financiadas pelo poder público, o que praticamente não acontece no Brasil.

92 CARVALHO, Patrícia Luciane de. Patentes Farmacêuticas e Acesso a Medicamentos. São Paulo: Atlas, 2007. p. 98.

93 PIVETTA, Saulo Lindorfer. Políticas públicas e a construção do conteúdo material do direito à saúde: desafio à Administração Pública brasileira. A\&C - Revista de Direito Administrativo \& Constitucional, Belo Horizonte, ano 3, n. 11, p. 221, jan/mar. 2003.

94 CANOTILHO, J. J. Gomes; MACHADO, Jónatas. A Questão da Constitucionalidade das Patentes “Pipeline” à Luz da Constituição Federal Brasileira de 1988. Coimbra: Almedina, 2008. p. 23.

95 GRAU-KUNTZ, Karin. Dignidade humana e direito de patentes: sobre o problema de acesso a medicamentos. In: CARVALHO, Patrícia Luciane de (Coord.). Propriedade Intelectual: estudos em homenagem à professora Maristela Basso. Curitiba: Juruá, 2005. p. 309-310. 
Considerando-se que os direitos de propriedade intelectual são basicamente bens particulares criados para a inovação, os demais fatores são responsabilidade direta dos governos. Paradoxalmente, alguns Estados, alguns doutrinadores e a opinião pública enfatizam a necessidade de controle do patrimônio intelectual dos particulares e das empresas, ao invés de exigir governos eficientes e eficazes. A propriedade intelectual é transitória no tempo, com limite certo de vinte anos. No entanto, a incompetência dos governos e sua incapacidade de coordenar-se e criar instituições eficazes são paradigmáticas e se arrastam por décadas. Dessa forma, enfatizar excessivamente a incidência da propriedade intelectual sobre o acesso aos medicamentos não deixa de ser uma incongruência. Isso não significa que o debate sobre patentes e o acesso aos medicamentos sejam supérfluos, mas sim que os problemas devem ser relativizados e ordenar as prioridades e os esforços. ${ }^{96}$

$\mathrm{O}$ direito ao acesso aos medicamentos é desrespeitado pelo Estado ante à insuficiência de políticas públicas proativas, preventivas e progressivas. Um desenvolvimento sustentável no que tange aos medicamentos diz respeito ao seu acesso e à fabricação, "seja pelo conhecimento tecnológico que deve ser incluído na agenda política, seja pelo aproveitamento do conhecimento para a produção de genéricos" que, infelizmente, no Brasil, até os dias de hoje, sofrem preconceito no que diz respeito à sua eficácia, pois vincula-se o preço à baixa eficácia. Há necessidade de uma indústria nacional de medicamentos genéricos, com capacidade para testes de bioequivalência e biodisponibilidade em relação ao medicamento de referência. Para isso, requer-se uma capacitação técnica, temporal e orçamentária. ${ }^{97}$

O Brasil possui alguns incentivos tributários ${ }^{98}$ para a pesquisa e desenvolvimento, inclusive de medicamentos. No entanto, não são voltados especificamente para as doenças raras, são comuns a qualquer fármaco. Possui, ainda, outras medidas de incentivo como, por exemplo, a criação da Câmara de Regulação do Mercado de Medicamentos, instituída em 2003 pela Lei no 10.742, órgão interministerial, composto pelo Ministério da Saúde, Fazenda, Justiça, Desenvolvimento e Casa Civil, que instituiu uma política voltada para a redução e administração do custo da aquisição

\footnotetext{
96 MUÑOZ, Silvia Valverde. Los derechos de propiedad intelectual y el acceso a los medicamentos, a nivel mundial. In: VELA, Rafael Barranco; SÁENZ, Francisco Miguel Bombillar. El Acceso al Medicamento: retos jurídicos actuales, intervención pública y su vinculación al derecho a la salud. Granada: Editorial Comares, 2010. p. 99.

97 CARVAlHO, Patrícia Luciane de. Patentes Farmacêuticas e Acesso a Medicamentos. São Paulo: Atlas, 2007. p. 150.

98 No que tange ao imposto de renda, na apuração do rendimento líquido para efeitos da tributação, são dedutíveis os custos de bens e serviços por elas comercializados e demais despesas necessárias ao exercício de suas atividades. Dentre as despesas dedutíveis encontram-se aquelas destinadas a pesquisas tecnológicas e científicas, incluindo as de experimentação para criação ou aperfeiçoamento de produtos, processos, técnicas e fórmulas de produção, administração ou venda. É admitida, ainda, a dedução como despesa da depreciação anual ou, em sendo abandonada a pesquisa por insucesso, o valor residual dos equipamentos e instalações. Em BARROS, Carla Eugênia Caldas. Manual de Direito da Propriedade Industrial. Aracajú: Evocati, 2007. p. 298-300.
} 
de medicamentos. Dentre as suas competências está o acesso aos medicamentos, sugerindo aos órgãos competentes a adoção de diretrizes e procedimentos voltados à implementação de políticas públicas de acesso aos medicamentos. ${ }^{99}$

Além disso, em 2004, na tentativa de estimular o desenvolvimento de inovações tecnológicas, o Brasil editou a Lei oㅜ 10.973, estabelecendo medidas de incentivo à inovação tecnológica e à pesquisa científica e tecnológica no ambiente produtivo. ${ }^{100}$ Outras políticas públicas federais de incentivo à pesquisa e ao desenvolvimento técnico-científico nacional estão sintetizadas em duas leis: a Lei no $10.168 / 00$ que versa sobre a Contribuição de Intervenção de Domínio Econômico - CIDE e a Lei no 11.196/05 denominada de "Lei do Bem", que dispõe sobre incentivos fiscais para inovação tecnológica. O capítulo III, "Dos Incentivos à Inovação Tecnológica", 101 recebeu regulamentação no Decreto № 5.798/06.

Ademais, está em tramitação no Senado Federal o Projeto de Lei oㅡ 231 de 2012, de autoria do Senador Eduardo Suplicy, visando à criação de um Fundo Nacional de Pesquisa para Doenças Raras e Negligenciadas (FNPDRN), com a finalidade de apoiar projetos de pesquisa e empreendimentos na área das doenças raras e negligenciadas. No entanto, mesmo sendo aprovado este Projeto de Lei, o Fundo servirá para realização de pesquisas, mais ainda não haverá incentivo para a continuidade da fabricação.

Assim, os medicamentos para doenças raras, por sua importância social, requerem do Poder Público um tratamento diferenciado, através de incentivos econômicos também para investimento na continuidade da fabricação daqueles fármacos. Cabe ao Estado instituir uma política pública voltada diretamente a estas doenças, inclusive quanto à fabricação do medicamento para seu tratamento. Isso porque a própria Constituição Federal estabelece, em seu art. 200,102 a participação do Estado junto à ordem econômica, através do SUS, na produção e incremento do desenvolvimento científico e tecnológico dos medicamentos.

Souza et al. ${ }^{103}$ defendem a criação de uma política de assistência farmacêutica específica para doenças raras no Brasil e apresentam vários motivos. 0 primeiro

99 Lei no 10.742/2003. Art. 6 Compete à CMED, dentre outros atos necessários à consecução dos objetivos a que se destina esta Lei: VII - sugerir a adoção, pelos órgãos competentes, de diretrizes e procedimentos voltados à implementação da política de acesso a medicamentos;

100 Para estudo dos incentivos: BARROS, Carla Eugênia Caldas. Manual de Direito da Propriedade Industrial. Aracajú: Evocati, 2007. p. 297 e ss.

101 O próprio legislador preocupou-se em definir o que seria inovação tecnológica no §1ำ do art. 17: “Considerase inovação tecnológica a concepção de novo produto ou processo de fabricação, bem como a agregação de novas funcionalidades ou características ao produto ou processo que implique melhorias incrementais e efetivo ganho de qualidade ou produtividade, resultando maior competitividade no mercado".

102 Art. 200. Ao sistema único de saúde compete, além de outras atribuições, nos termos da lei:

I - controlar e fiscalizar procedimentos, produtos e substâncias de interesse para a saúde e participar da produção de medicamentos, equipamentos, imunobiológicos, hemoderivados e outros insumos;

103 SOUZA, Mônica Vinhas de et al. Medicamentos de Alto Custo para Doenças Raras no Brasil: o exemplo das doenças lisossômicas. Ciência e Saúde Coletiva, v. 15, n. 3, nov. 2010. Disponível em: <http://redalyc. uaemex.mx/pdf/630/63015154015.pdf>. Acesso em: 04 maio 2012. p. 3451. 
deles é que normalmente as doenças genéticas constituem um dos principais grupos de doenças raras e são causa importante de mortalidade infantil no país. Segundo, refere-se à gravidade das doenças raras que, em muitos casos, ameaçam a vida. Terceiro motivo é que o número de pacientes diagnosticados com doenças raras, embora seja ainda pequeno, tende a aumentar, em virtude do aumento da busca de diagnósticos. Quarto motivo refere-se ao custo do medicamento que, normalmente, é muito elevado. 0 quinto é que a maioria dos tratamentos para as doenças raras, especialmente as genéticas, não são fortemente baseados em evidências nem foram avaliados em relação a aspectos de custo-efetividade. Isso em razão, dentre outros aspectos, da falta de dados sobre história natural, de estímulo a esse tipo de pesquisa e de ensaios clínicos adequados. Além disso, existe a falta de transparência (sexto motivo) em relação à inclusão ou exclusão de medicamentos nas listas do SUS, o que privilegia certos grupos de doenças ou de pacientes. O sétimo motivo refere-se ao fato de que existe variabilidade na conduta dos Estados brasileiros em relação à implementação de programas para o atendimento dessas doenças. E, o último, mas não menos importante motivo, reporta ao fato de que a maioria dos medicamentos para as doenças raras não incluídos em listas são obtidos por meio de demandas judiciais. Para muitos destes pacientes a necessidade de tratamento existe e não pode ser adiada pela falta de política eficiente ou pelos gastos não justificados em medicamentos sem eficácia e segurança comprovadas.

Portanto, o que se pode perceber é que já passou da hora de o Brasil seguir o exemplo dos Estados Unidos e da União Europeia e instituir política pública para as doenças raras, principalmente concedendo incentivos para que os laboratórios farmacêuticos, além de criarem novos medicamentos, continuem fabricando os que já existem de maneira a atender todos os pacientes que deles necessitem.

\section{Conclusão}

O desenvolvimento de um novo medicamento demanda altos investimentos. Sendo assim, não se pode estranhar que as indústrias farmacêuticas deixem de fabricar medicamentos para doenças raras por serem pouco rentáveis. Dessa forma, o ordenamento jurídico viu-se obrigado a proteger o setor, incluindo os fármacos entre os produtos patenteáveis e, consequentemente, protegendo sua propriedade industrial, com o intuito de estimular a pesquisa e o desenvolvimento de medicamentos. O reconhecimento do direito de patente confere ao seu titular a exploração exclusiva do medicamento, no entanto, esta exploração não pode se dar de forma abusiva. 0 titular da patente deve observar a função social da propriedade. A efetivação desta função social não é dever apenas da iniciativa privada, mas também ao Estado que deve estar atento para que a propriedade não se restrinja apenas à obtenção de lucro, mas que atenda também à saúde da população. 
Quando o detentor da patente de um produto farmacêutico deixar de atender a sua função social, caberá ao Estado reestabelecer a ordem através de mecanismos como, por exemplo, a intervenção na propriedade privada, fazendo a desconstituição do direito de exclusividade, através do licenciamento compulsório.

Como o Brasil não possui política pública voltada exclusivamente para as doenças raras, no caso de os laboratórios farmacêuticos deixarem de fabricar medicamentos para estas doenças, existem alguns mecanismos no ordenamento jurídico brasileiro que podem ser utilizados para tentar alcançar este fim: a licença compulsória, a importação paralela e consequente fabricação de medicamentos genéricos. Entre os deveres do titular da patente encontra-se o dever de sua exploração. Assim, caso não explore o bem, como acontece com os medicamentos para doenças raras, o Estado, no intuito de promover a saúde, poderá intervir na propriedade privada para garantir que o fármaco possa chegar ao paciente. Dá-se aqui o licenciamento compulsório pela inexploração da patente. Uma vez quebrada a patente do medicamento, abre-se a possibilidade da importação paralela, mecanismo importante para suprir as falhas da indústria farmacêutica em atender as necessidades de mercado, possibilitando a aquisição, inclusive, de medicamentos mais baratos. No entanto, os institutos da licença compulsória e da importação paralela não são aptos a solucionarem os problemas da interrupção na fabricação de medicamentos para doenças raras. Primeiro, porque são pouco utilizados e, segundo, porque mesmo quando utilizados referem-se a um medicamento de cada vez, sendo apenas uma resolução pontual.

Uma vez quebrada a patente e não havendo mais o direito de exclusividade do titular da patente, uma das consequências é a possibilidade de fabricação, por laboratório público ou privado, do medicamento genérico. No entanto, o Brasil fica limitado, mesmo após a expiração do direito de propriedade intelectual, pois não há laboratórios evoluídos para produção de genéricos. Necessário que o Brasil aperfeiçoe e crie novos laboratórios para a produção nacional dos fármacos genéricos. Outra necessidade para o desenvolvimento de medicamentos genéricos no Brasil é o eficaz funcionamento dos órgãos administrativos, colaborando com a proteção às patentes farmacêuticas e com o acesso aos medicamentos. 0 país pode estabelecer algumas medidas ou exceções com o objetivo de promover a rápida entrada dos produtos genéricos no mercado consumidor, após a expiração das patentes. Uma possibilidade é a concessão do efeito Bollar, ou seja, antes de expirado o prazo de uso exclusivo do fármaco patenteado, possam realizar pesquisas acerca do medicamento referencial. Verificou-se que a possibilidade de produção dos genéricos no Brasil é pouco utilizada e que, portanto, não colabora para que os portadores de doenças raras possam ter acesso aos medicamentos que deixam de ser fabricados.

Diferentemente do Brasil, apesar da enorme diferença entre os sistemas públicos de saúde, Estados Unidos e União Europeia adotam uma política pública 
para o estímulo da produção dos medicamentos para doenças raras, outorgando às indústrias farmacêuticas vários incentivos. Estes incentivos já apresentaram bons resultados na criação e produção de medicamentos órfãos. O Brasil, da mesma forma, deveria estabelecer uma política pública para o incentivo de criação e produção de medicamentos para doenças raras. Até mesmo porque o medicamento para doenças raras, por sua importância social, requer do Poder Público um tratamento diferenciado, através de incentivos econômicos também para investimento na continuidade da fabricação destes fármacos.

\section{The Need of Public Policy to Rare Disease's Medication}

Abstract: This study had, as its object, the rare disease medication, that are not manufactured by pharmaceutical laboratories once it lacks profitability. It was found that Brazilian law offers some mechanisms that could ensure access to the medication by rare disease carriers, as the case of compulsory licensing and the parallel importation. However, these mechanisms resolve the singular problem of the medication one by one and they don't consist in a definitive solution to the problem. It was tried, so, to analyze the public policy implemented in the United States and European Union to encourage researches, fabrication and the continued production of the rare diseases medication. It was concluded that Brazil should institute a public policy exclusively intended to the medication manufacturing so that it can guarantee effectively the fundamental right to health.

Key words: Medication. Rare Disease. Public Policy.

\section{Referências}

BARBOSA, Dênis Borges; BARBOSA, Ana Beatriz Nunes; GRAU-KUNTZ, Karin. A Propriedade Intelectual na Construção dos Tribunais Constitucionais. Rio de Janeiro: Lumen Juris, 2009.

BARROS, Carla Eugênia Caldas. Manual de Direito da Propriedade Industrial. Aracajú: Evocati, 2007.

BENETTI, Daniela Vanila Nakalski. Positivação e (in)eficácia da licença compulsória frente ao "novo bilateralismo" comercial. In: ADOLFO, Luiz Gonzaga Silva; MORAES, Rodrigo (Coord.). Propriedade Intelectual em Perspectiva. Rio de Janeiro: Lumen Juris, 2008.

BEZERRA, Matheus Ferreira. Patente de Medicamentos: quebra de patente como instrumento de realização do direito. Curitiba: Juruá, 2010.

BRASIL. Conselho Nacional de Saúde. Assistência Farmacêutica no SUS. Brasília: CONASS, 2011.

CANOTILHO, J. J. Gomes; MACHADO, Jónatas. A Questão da Constitucionalidade das Patentes “Pipeline” à Luz da Constituição Federal Brasileira de 1988. Coimbra: Almedina, 2008.

CARVAlHO, Patrícia Luciane de. Patentes Farmacêuticas e Acesso a Medicamentos. São Paulo: Atlas, 2007.

DALLARI, Sueli Gandolfi; NUNES JÚNIOR, Vidal Serrano. Direito Sanitário. São Paulo: Verbatim, 2010.

GRANGEIRO, Alexandre et al. Propriedade Intelectual, Patentes \& Acesso Universal a Medicamentos. São Paulo: Grupo de Incentivo à Vida/Grupo pela Vidda-SP/Centro de Referência e Treinamento em DST/AIDS de São Paulo/Instituto de Saúde, 2006. 
GRAU-KUNTZ, Karin. Dignidade humana e direito de patentes: sobre o problema de acesso a medicamentos. In: CARVALHO, Patrícia Luciane de (Coord.). Propriedade Intelectual: estudos em homenagem à professora Maristela Basso. Curitiba: Juruá, 2005.

HAFFNER, Marlene E. The United States Orphan Drug Act: challenges and success. Drug Information Journal, v. 31, 1997.

HUGHES, D. A.; TUNNAGE, B.; YEO, S. T. Drugs for exceptionally rare diseases: do they deserve special status for funding?. Disponível em: <http://qjmed.oxfordjournals.org/>. Acesso em: 04 mar. 2012.

KATARIA, Mahesh Kumar et al. An Insight on Regulations Governing Orphan Diseases and Drugs. Research Journal of Pharmaceutical Biological and Chemical Sciences, v. 2, Jul./Set. 2011.

KRELL, Andreas. Direitos Sociais e Controle Judicial no Brasil e na Alemanha. Porto Alegre: Sergio Antonio Fabris, 2002.

LIMBERGER, Têmis; SALDANHA, Jânia Maria Lopes. O direito à saúde e sua efetividade: o debate democrático perante o Supremo Tribunal Federal. Interesse Público, Belo Horizonte, ano 12, n. 64, nov./dez. 2010.

MAGALHÃES, Carina da Conceição Carvalho. A Patenteabilidade da Indústria Farmacêutica: 0 Interesse Público na Protecção da Saúde. Dissertação (Mestrado). Programa de Pós-Graduação em Direito. Universidade de Porto. Porto, 2012. Disponível em: <http://repositorioaberto.up.pt/ bitstream/10216/63873/2/Tese\%20\%20Carina\%20Magalhes.pdf>. Acesso em: 20 jan. 2012.

MÉDICOS Sem Fronteira. A Nova Crise de Acesso a Medicamentos Anti-Aids: preços de anti-retrovirais financeiramente inviáveis... novamente. Disponível em: <www.deolhonaspatentes.com.br>. Acesso em: 29 nov. 2012.

MUÑOZ, Silvia Valverde. Los derechos de propiedad intelectual y el acceso a los medicamentos, a nivel mundial. In: VELA, Rafael Barranco; SÁENZ, Francisco Miguel Bombillar. El Acceso al Medicamento: retos jurídicos actuales, intervención pública y su vinculación al derecho a la salud. Granada: Editorial Comares, 2010.

PIVETTA, Saulo Lindorfer. Políticas públicas e a construção do conteúdo material do direito à saúde: desafio à Administração Pública brasileira. A\&C - Revista de Direito Administrativo \& Constitucional, Belo Horizonte, ano 3, n. 11, jan./mar. 2003.

SCUDELER. Marcelo Augusto. A Função Social da Propriedade Industrial. In. VELÁZQUEZ, Victor Hogo Tejerina (Org.). Propriedade Intelectual: setores emergentes e desenvolvimento. Piracicaba: Equilibro, 2007.

SEOANE-VAZQUÉZ, Enrique et al. Incentives for Orphan Drug Research and Development in the United States. Orphanet Journal of Rare Diseases, 2008. Disponivel em: <http//www.ojrd.com/ content/3/1/33>. Acesso em: 24 fev. 2012.

SILVA, Regina Célia dos Santos. Medicamentos excepcionais no âmbito da assistência farmacêutica no Brasil. [Mestrado] Fundação Oswaldo Cruz, Escola Nacional de Saúde Pública; 2000. 215p. Disponivel em: <http://portalteses.icict.fiocruz.br/transf.php?script=thes_chap\&id=00006205\&lng $=$ pt\&nrm=iso $>$. Acesso em: 16 set. 2011.

SOUZA, Mônica Vinhas de et al. Medicamentos de Alto Custo para Doenças Raras no Brasil: o exemplo das doenças lisossômicas. Ciência e Saúde Coletiva, v. 15, n. 3, nov. 2010. Disponível em: <http:// redalyc.uaemex.mx/pdf/630/63015154015.pdf>. Acesso em: 04 maio 2012.

STOLK, Pieter; WILLEMEN, Marjolein J. C.; LEUFKENS, Hubert G. N. "Rare Essencials": drugs for rare as essencial medicines. Bulletin of the World Health Organization, n. 84, 2006.

TIMM, Luciano Benetti; BRAGA, Rodrigo Bernardes (Org.). Propriedade Intelectual. Belo Horizonte: Arraes Editores, 2011. 
VARGAS, Fábio Aristimunho. O regime internacional de proteção do acesso a medicamentos: um enfoque social. In: CARVALHO, Patrícia Luciane de (Coord.). Propriedade Intelectual: estudos em homenagem à professora Maristela Basso. Curitiba: Juruá, 2005.

VELA, Rafaela Barranco. El Estatuto Jurídico de los medicamentos huérfanos en la Unión Europea: el derecho de la salud de los pacientes com enfermidades raras. In: VELA, Rafael Barranco; SÁENZ, Francisco Miguel Bombillar (Org.). El Acceso al Medicamento: retos jurídicos actuales, intervención pública y su vinculación al derecho de la salud. Granada: Editorial Comares, 2010.

VIZZOTTO, Alberto. A Função Social das Patentes sobre Medicamentos. São Paulo: LCTE, 2010.

WEELY, S. van; LEUFKENS, H. G. M. Orphan Diseases: priority medicines for Europe and the world: "A public health approach to innovation". Background Paper, 2004.

WIEST, Ramon. A Economia das Doenças Raras: teorias, evidências e políticas públicas. Monografia. Departamento de Ciências Econômicas. Faculdade de Ciências Econômicas da Universidade Federal do Rio Grande do Sul. Porto Alegre, 2010.

Informação bibliográfica deste texto, conforme a NBR 6023:2002 da Associação Brasileira de Normas Técnicas (ABNT):

GLOECKNER, Joseane Ledebrum. Da necessidade de uma política pública voltada aos medicamentos para doenças raras. A\&C - Revista de Direito Administrativo \& Constitucional, Belo Horizonte, ano 15, n. 61, p. 233-262, jul./set. 2015.

Recebido em: 16.04.2014

Aprovado em: 08.11.2014 